\title{
Lifetime of soil moisture perturbations in a coupled land-atmosphere simulation
}

\author{
T. Stacke and S. Hagemann \\ Max Planck Institute for Meteorology, Bundesstrasse 53, 20146 Hamburg, Germany \\ Correspondence to: T. Stacke (tobias.stacke@mpimet.mpg.de) \\ Received: 26 August 2015 - Published in Earth Syst. Dynam. Discuss.: 11 September 2015 \\ Revised: 17 November 2015 - Accepted: 6 December 2015 - Published: 18 January 2016
}

\begin{abstract}
In order to evaluate whether the initialization of soil moisture has the potential to improve the prediction skill of earth system models (ESMs) on seasonal to decadal timescales, an elaborate experiment was conducted. For this task a coupled land-atmosphere model with prescribed ocean was utilized. The experiment design considered soil moisture initialization in different seasons and years and yielded information about the lifetime (memory) of extreme yet realistic soil moisture perturbations. Our analyses were focused on root zone soil moisture (RootSM) as it comprises the part of the soil that directly interacts with the atmosphere via baresoil evaporation and transpiration. We found that RootSM memory differs not only spatially but also depends on the time of initialization. A long memory of up to 1 year is evident mostly for dry soil moisture regimes after heavy precipitation periods or prior to snow covered conditions. Short memory below 2 weeks prevails in wet soil moisture regimes and prior to distinct precipitation periods or snowmelt. Furthermore, RootSM perturbations affect other land surface states, e.g. soil temperature and leaf carbon content, and even induce anomalies with specific memory in these variables. Especially for deep-layer soil temperature, these anomalies can last for up to several years. As long as RootSM memory is evident, we found that anomalies occur periodically in other land surface states whenever climate conditions allow for interactions between that state and RootSM. Additionally, anomaly recurrence is visible for RootSM itself. This recurrence is related to the thickness of the soil layer below the root zone and can affect RootSM for several years. From our findings we conclude that soil moisture initialization has the potential to improve the predictive skill of climate models on seasonal scales and beyond. However, a sophisticated, multilayered soil hydrology scheme is necessary to allow for the interactions between RootSM and the deep-soil layer reservoir.
\end{abstract}

\section{Introduction}

Until recently, the main application for earth system models (ESMs) was the reproduction or projection of long-term climate statistics over periods of 30 years or longer (K. E. Taylor et al., 2012). However, during the last decade this focus was expanded towards decadal (Meehl et al., 2009) and seasonal predictions (Palmer et al., 2004). On such timescales, it is not only the quality of model physics and the external forcing that play a major role but also an appropriate initialization of state variables (Pohlmann et al., 2009; Müller et al., 2014). In the climate community, the potential of initialization is investigated focusing mostly on decadal predictions and the state of the ocean (e.g. Keenlyside et al., 2008;
Pohlmann et al., 2009; Matei et al., 2012). However, especially for short-term simulations such as numerical weather forecasts or reanalysis, the land surface has also been identified as an interesting target for initializations. Initialization experiments focusing on snow cover (Douville and Royer, 1996; Jeong et al., 2013) and soil moisture (Atlas et al., 1993; Betts, 2004; Fischer et al., 2007; Beljaars et al., 1996; Small, 2001; Kim and Hong, 2007; Koster and Suarez, 2003) are shown to affect the climate state, and therefore their initialization can be expected to enhance the predictive skill of an ESM. 
The reason for the importance of initialization is the interaction between land surface and atmospheric states, which is rather complex and results in a number of feedbacks (e.g. Bony et al., 2006). Of those, one of the most investigated processes are soil moisture feedbacks (e.g. Dirmeyer and Shukla, 1993; Eltahir, 1998; Seneviratne et al., 2010). They rely on the important role that soil moisture plays in both the terrestrial water balance as well as the energy balance. On the one hand, soil moisture determines the separation of incoming water fluxes into surface runoff and infiltration. Surface runoff is transported into rivers and leaves a given region. Infiltrated water adds to the soil moisture and might be available for evapotranspiration again. Thus, soil moisture strongly affects the regional water balance. On the other hand, both energy and water balance, can be affected simultaneously via the evapotranspiration flux. Depending on the state of soil moisture, incoming short wave radiation is separated into latent and sensible heat flux. This affects both the water and the energy balance as the latent heat flux transports not only energy but also water to the atmosphere. From this, two major soil moisture feedbacks arise. The first feedback is between soil moisture and temperature. Wet or dry soil moisture anomalies directly affect the partition between latent and sensible heat flux. Wetter (drier) soils lead to increased (decreased) latent heat flux and evapotranspiration, therefore extracting more (less) water from the soil, which might result in compensating for the soil moisture anomaly and thus form a negative feedback loop. However, the associated changes in sensible heat flux and latent cooling lower (increase) surface temperature and thus also decrease (increase) evaporative demand. If the effect of changes in evaporative demand on evapotranspiration is stronger than the direct effect of the changed soil moisture state, the soil moisture-temperature coupling can result in a positive feedback. Thus, the soil moisture anomaly can be stabilized or even enhanced. A second feedback is based on the coupling between soil moisture and precipitation. Here precipitation anomalies result in subsequent anomalies in soil moisture which then affect evapotranspiration. At this point, the feedback loop can be already interrupted if the precipitation anomaly is smaller than the change in evapotranspiration and cannot sustain the anomaly in the soil. Otherwise, the evapotranspiration anomaly can effect precipitation either locally or in downwind regions. An alternative to the direct recycling of evaporated water as precipitation, it was also proposed that the effect on precipitation happens rather because anomalous soil surfaces impact the distribution of boundary layer moist static energy (Eltahir, 1998). More detailed information about soil moisture interactions and feedbacks can be found in Seneviratne et al. (2010) and references therein.

A large number of studies exist which investigate the impact of soil moisture anomalies on the terrestrial climate on different temporal and spatial scales. One objective of these studies is the reproduction of specific seasonal climate conditions and the analysis of their dependence on soil moisture states (Atlas et al., 1993; Ferranti and Viterbo, 2006; Fischer et al., 2007). These studies demonstrate that extreme climate conditions are more likely to occur if extensive soil moisture anomalies existed in the past season. Additionally, there are several sensitivity studies investigating the effect of soil moisture anomalies on different regions such as the North American (Beljaars et al., 1996; Small, 2001; Betts, 2004), African and/or Asian monsoon regions (Douville et al., 2001; Kim and Hong, 2007) and Europe (Rowntree and Bolton, 1983; Jaeger and Seneviratne, 2011). Often, but not always, prescribing positive soil moisture anomalies is correlated with the simulation of enhanced precipitation in the following season and vice versa. The persistence of soil moisture anomalies is also investigated in several studies, e.g. Manabe and Delworth (1990), Huang et al. (1996), Koster and Suarez (2001), Betts (2004), Wu and Dickinson (2004), Seneviratne et al. (2006), Dirmeyer et al. (2009), and Hagemann and Stacke (2015). Estimates for soil moisture memory range between 1 and 6 months but differ based on the methods and models used to investigate it. Manabe and Delworth (1990) found short memory of 1-2 months for low latitudes with increases of up to 5 months in high latitudes, peaking in a memory of up to 10 months in northern Siberia. For Europe they found a memory of 2-3 months, which agrees well with Ferranti and Viterbo (2006). Some similarities exist also with the results of Hagemann and Stacke (2015), especially for regions with short memory. However, they found a shorter memory for northern Siberia and a memory longer than 1 year for desert regions. Most studies, however, do not explicitly compute the soil moisture memory but rather estimate its length based on a prescribed decay function of the soil moisture autocorrelation coefficient for a given lag (often 1 month) (Huang et al., 1996; Koster and Suarez, 2001; Betts, 2004; Wu and Dickinson, 2004; Seneviratne et al., 2006). The resulting soil moisture memory ranges between 1 and 10 months and shows a spatial pattern with long memory in arid regions and high latitudes and short memory for monsoon-influenced regions. Seasonal variations in soil moisture memory were analysed by Dirmeyer et al. (2009). Looking at daily statistics they found considerably shorter memory, which exceeds one season only for desert or energylimited regions during the respective seasons. Soil moisture memory estimates based on observations are extremely rare but are roughly in the same order of magnitude as most modelling studies. Based on 50 measurement sites across the former USSR, Vinnikov and Yeserkepova (1991) computed a soil moisture memory ranging from 1 to 5 months, while Shinoda and Nandintsetseg (2011) found a seasonally varying memory of between 1.5 and 8 months for 24 stations in Mongolia.

Most of these studies have in common that they investigated the effect of soil moisture perturbations or soil moisture memory for a very limited time period, usually focusing on the next season. Although the results indicate that soil moisture memory might be much longer for several regions, 
only little information exists about the maximum time period for which soil moisture perturbations can be expected to affect climate simulations. Considering recent projects focusing on seasonal to decadal prediction systems (see MiKlip (Mittelfristige Klimaprognosen) http://www.fona-miklip. de/en/ and SPECS (Seasonal-to-decadal climate Prediction for the improvement of European Climate Services) http: //www.specs-fp7.eu/), it would be valuable to learn more about the potential of soil moisture initialization. Particularly, information about the persistence of soil moisture perturbations in ESMs can contribute to decisions about the necessity to initialize soil moisture in short- or even long-term predictions.

For this reason we set up an experiment to investigate the lifetime of soil moisture perturbations for different seasons. In contrast to previous work by Hagemann and Stacke (2015), the focus is not on the general impact of soil representation on soil moisture autocorrelation length. Instead, we analyse the impact of root zone soil moisture (RootSM) initialization for different seasons and regions. In our paper we first describe the model characteristics, experiment set-up and the analysis methods applied. Following this we present the distribution of soil moisture memory and its variance throughout the year. Next, the origin of soil moisture memory is investigated, and its relation to different soil properties and climate variables is discussed. Finally, we contrast our findings against knowledge gained from previous studies and give directions for further research.

\section{Experiment set-up and analysis methods}

The soil moisture initialization experiment uses the coupled atmosphere-land model ECHAM6/JSBACH (Stevens et al., 2013; Raddatz et al., 2007) with prescribed ocean fields (PCMDI AMIP2) of sea surface temperature and sea ice concentration for the appropriate time periods (Taylor et al., 2000). All simulations are conducted with a horizontal resolution of $\mathrm{T} 63\left(\approx 1.8^{\circ}\right)$ and 47 vertical levels for the atmosphere. While most of the set-up is identical to the CMIP5 (Coupled Model Intercomparison Project Phase 5) set-up (Giorgetta et al., 2013), the standard JSBACH soil module is replaced with the new five-layer soil hydrology scheme (Hagemann and Stacke, 2015). In contrast to the former bucket scheme, this scheme separates the soil into five distinct layers to a maximum depth of about $10 \mathrm{~m}$ or the bedrock. The topsoil layer is the reservoir for bare-soil evaporation. The accumulated moisture in the upper layers within the rooting depth is defined as RootSM and is subject to transpiration. The layers below are associated with the deep-zone soil moisture (DeepSM). As the latter is not directly accessible by plants, it can loose water only by drainage or diffusion into upper soil layers. Thus, the deep layers are often equivalent to long-term water storage and were shown to improve the representation of soil moisture memory in JSBACH com-

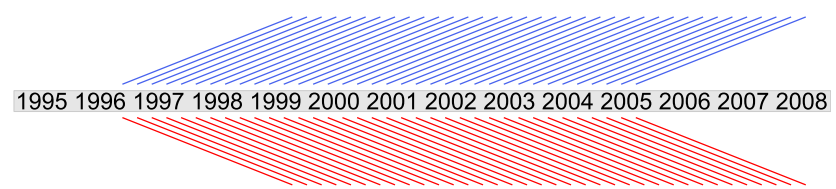

Figure 1. Schematic of the soil moisture initialization experiment set-up. The grey bar indicates the time line of REF while the blue and red lines indicate the extreme wet and dry INI, respectively.

pared to the standard bucket scheme (Hagemann and Stacke, 2015). It is important to note that the applied version of JS$\mathrm{BACH}$ does not consider any melting and freezing processes within the soil. Thus, there is no interaction between water and energy states within the soil column, and soil moisture anomalies can effect soil temperature only via the pathway of evapotranspiration and surface temperature.

The soil moisture initialization experiment is composed of two sets of simulations. The first set consists of one reference simulation (REF) for the period 1995-2008. Its initial states were taken from an earlier spin-up simulation running over several decades. For every year and month, restart data are generated by the model and 6-hourly averages of the RootSM and of the soil moisture for the individual soil layers (LaySM) are stored. From these data, extreme wet and dry soil moisture states are extracted as initial conditions for the second set of initialized simulations (INI). The INI are restarted at the start of every season for the years between December 1996 and September 2005, running freely for 3 years (see Fig. 1). No INI are started prior to December 1996 as this time is regarded as additional spin-up for the model to adapt to minor differences in the forcing between the REF and the spin-up simulation. Thus, this experiment yields ensembles consisting of nine members (one for each year) per restart month (4) and initialization state (2), accumulating to $9 \times 4 \times 2$ simulations resulting in a data set of 216 simulation years.

In contrast to previous soil moisture initialization experiments (e.g. Betts, 2004; Ferranti and Viterbo, 2006; Fischer et al., 2007; Jaeger and Seneviratne, 2011), the initial soil fields are not defined as a fixed percentage of the reference value nor set to a known critical state such as wilting point or maximum soil water holding capacity. Instead the 6-hourly output for the period of \pm 15 days around a given restart time was extracted for every year from REF and merged into one time series. From the time series, the 99th and 1st percentiles of RootSM were identified. These percentile fields serve as extreme wet and dry RootSM initializations, respectively. For LaySM initialization, data from the same time steps were used to be consistent with the RootSM fields. Following this procedure, restart fields were computed for the 1st of December, March, June, and September. While the absolute values of the initialization data are identical for the respective months for every year, it has to be noted that their differences to the reference state vary from year to year. Instead of 
constant soil moisture perturbations, a distribution of perturbations is generated with minimum perturbation in the year where the reference state is close to the respective percentile and maximum perturbation when the reference climate conditions are opposite to the initial state. In this way, the perturbations range within model-realistic bounds because they are based on model data. Thus, we avoid unrealistic perturbations that would result in causing spin-up behaviour (large model drifts) rather than triggering soil moisture memory. Furthermore, the ensemble does not only consider the internal variability within the model but additionally takes interannual climate variations into account. This is also true for the majority of state variations in our ocean-surface forcing except for small parts of the North Atlantic region. There, our experiment cannot sample the full cycle of state variations and a tendency towards warm surface temperature anomalies remains.

The analysis is focused on the evaluation of soil moisture memory. In our study we diagnose memory for those time steps where the ensemble mean anomaly (EnsMean) - originating from the initial perturbation - exceeds the ensemble standard deviation (EnsStd). This is determined by the signal-to-noise ratio (SNR) for a given time step $i$ as

$\operatorname{SNR}(i)=\frac{E\left[\Delta \theta_{j}(i)\right]}{\sqrt{E\left[\left(\Delta \theta_{j}(i)-E\left[\Delta \theta_{j}(i)\right]\right)^{2}\right]}}$,

where $\Delta \theta_{j}$ is the difference in the respective target variable between daily means of INI and REF for an ensemble member $j$ and $E[]$ indicates the mean over all ensemble members. From this, two different memory quantities are derived. First, the initial perturbation length $\left(\tau_{0}\right)$, which we define as the period between the first occurrence of memory until the time step at which the initial perturbation is forgotten, and the INI ensemble mean state cannot be distinguished from the REF state any more. Some variables such as DeepSM may have a time lag $\left(\tau_{\mathrm{lag}}\right)$ before the perturbation reaches the layer and memory occurs. This has to be accounted for in the definition of $\tau_{0}$. The second quantity is the overall memory $\left(\tau_{\max }\right)$ which is the sum of all time steps showing memory. These memory quantities are given as

$$
\begin{aligned}
\tau_{\text {lag }} & =\min _{i=1 \ldots n}(i: \operatorname{SNR}(i)>1), \\
\tau_{0} & =\min _{i=1 \ldots n}\left(i: \operatorname{SNR}(i) \leq 1 \cap i \geq \tau_{\text {lag }}\right)-\tau_{\text {lag }},
\end{aligned}
$$

and

$\tau_{\max }=\sum_{i=1}^{n} k(i)$, where $k(i):=\left\{\begin{array}{l}1 \text { if } \operatorname{SNR}(i)>1 \\ 0 \text { if } \operatorname{SNR}(i) \leq 1,\end{array}\right.$

where $n=1095$ is the maximum number of time steps equivalent to the 3-year simulation period. Further important metrics are the initial perturbation $\left(\Delta \theta_{0}\right)$ and extreme anomaly $\left(\Delta \theta_{\max }\right)$ of a time series. The former is the peak anomaly in the initial memory period and for RootSM usually evident at the first time step. The latter is the 99th percentile in the anomaly time series during all memory periods. As the ensemble size of $j=9$ for a given season and initialization is rather small, our analyses are usually based on combined ensembles where either all seasons for a given initialization $(j=36)$ or both initializations for a given season $(j=18)$ are merged.

The memory analysis is demonstrated in Fig. 2 for RootSM in an arbitrary grid cell and seasonal ensemble. In this example $\tau_{0}$ for the extreme wet initialization is almost 1 month while the dry perturbation lasts distinctively longer, up to about 2.5 months.

Several analyses in this study are based on the spatial correlation between $\tau_{0}$ and other quantities, e.g. $\Delta \theta_{0}$. As $\tau_{0}$ is usually not normally distributed, neither spatially nor temporally, we apply the Spearman's rank correlation for those analyses, computed as

$$
\rho=\frac{\sum_{i}\left(R\left(x_{i}\right)-\overline{R_{x}}\right)\left(R\left(y_{i}\right)-\overline{R_{y}}\right)}{\sqrt{\sum_{i}\left(R\left(x_{i}\right)-\overline{R_{x}}\right)^{2}} \sqrt{\sum_{i}\left(R\left(y_{i}\right)-\overline{R_{y}}\right)^{2}}} .
$$

Furthermore, the spatial correlation between variables is affected by the spatial autocorrelation within the individual variables, resulting in too significant a correlation coefficient. We account for this effect by using a subsampling technique, where consecutively only a small, randomly chosen sample of locations is analysed at a time until eventually the full field is sampled. As the size of these samples is much smaller than the full field, we assume that the selection of autocorrelated locations within an individual sample is very improbable. Nonetheless, we repeat this analysis up to 10000 times or until the variation in the resulting significance is smaller than $5 \%$.

\section{Soil moisture memory}

The evaluation of the soil moisture initialization experiment is focused on a global analysis of memory distribution as well as a comparison of its characteristics for different regions and seasons. Additionally, relations between memory and anomalies are investigated.

Figure 3 displays statistics for soil moisture $\Delta \theta_{0}$ and $\tau_{0}$. The wet and dry initial perturbations are of similar magnitude for the respective soil moisture layers with no strong variations among the seasons. The initial ensemble mean perturbations for RootSM reach almost $\pm 0.2 \mathrm{~m}$. Variations are smallest $( \pm 0.01 \mathrm{~m})$ for the uppermost layer, which is also the least thick $(0.07 \mathrm{~m})$. The $\Delta \theta_{0}$ increase with increasing soil depth and layer thickness and reach a maximum of $\pm 0.25 \mathrm{~m}$ in the fourth layer. They decrease again for the fifth layer because this layer is often cut off by the bedrock and thus its global average is less thick than that of the third and fourth layer. In many cases, the lowest layers are often not perturbed 


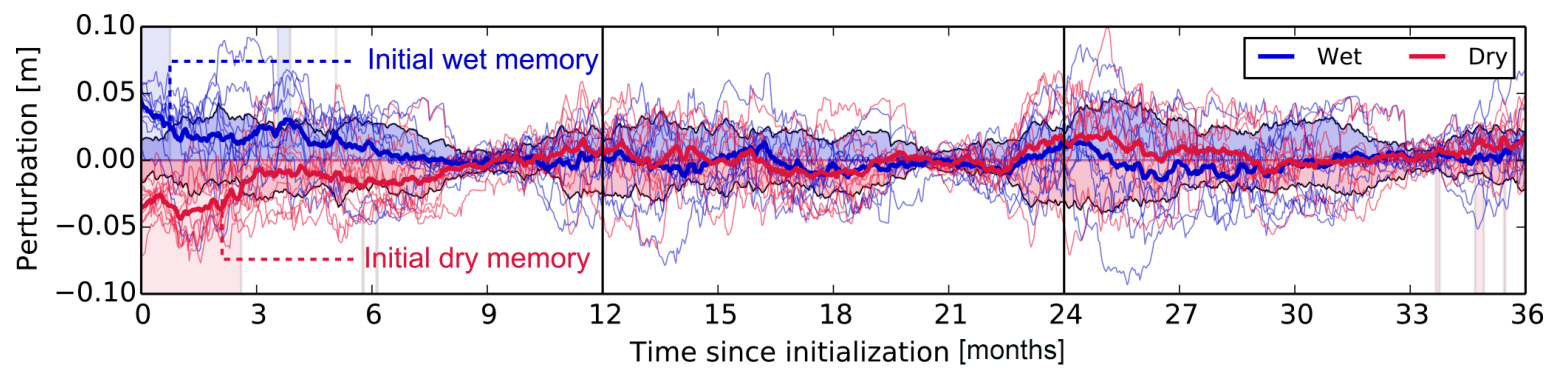

Figure 2. Example for soil moisture perturbation on grid cell scale (June ensemble; grid cell near Hamburg, Germany). The thick blue and red lines indicate the ensemble mean wet and dry perturbation, respectively. The thin lines are single ensemble members and the filled area displays the ensemble standard deviation.
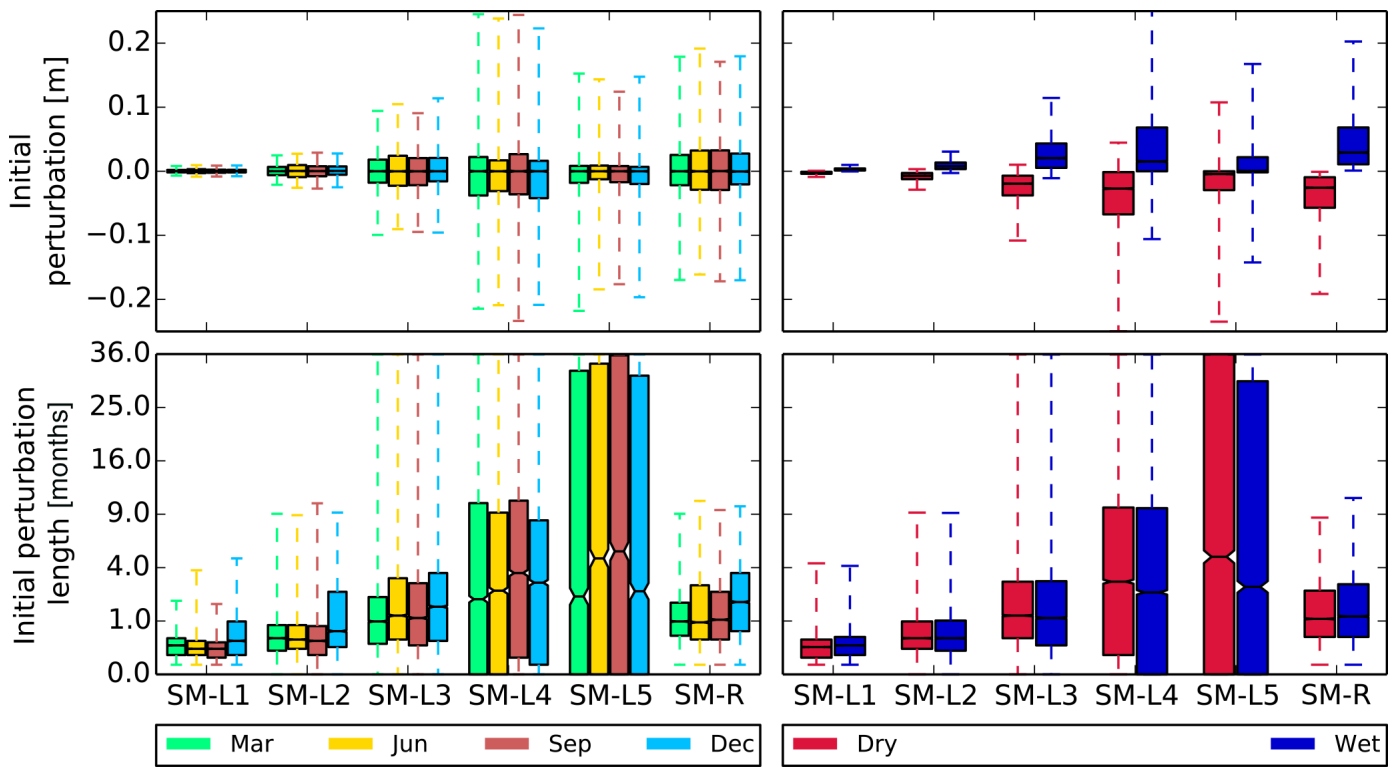

Figure 3. Initial perturbation $\Delta \theta_{0}$ (upper panels) and perturbation length $\tau_{0}$ (lower panels) statistics subdivided into seasonal ensembles (left) as well as into wet and dry initialized ensembles (right). Metrics are shown for soil layer moisture (SM-L1-5]) and the root zone soil moisture (SM-R) for all land surface grid cells. The whiskers indicate the 1st and 99th percentiles, the box indicates the interquartile range, and the notch indicates the median. Note the quadratic axis for $\tau_{0}$.

directly, as they can lie below the root depth and, thus, are not necessarily in a similarly extreme state. Consequently, only for the RootSM the wet and dry initialized simulations correspond perfectly to wet and dry initial perturbations, while the single layers show much more variance for this. Already for the topsoil layer, a small number of grid cells exist with initially wet perturbations for an overall dry root zone and vice versa. This effect increases with depth to about $20 \%$ of grid cells in the fifth layer which show the opposite perturbation signal from the RootSM. Analysis of memory time series show that in such cases the initial RootSM perturbations need some time to propagate into the deeper layers. This effect is negligible for layers within the root zone but results in a perturbation delay of over 30 (10) days for $25 \%$ of fifth-layer cells for wet (dry) initialization.
The lifetimes $\tau_{0}$ of these perturbations vary strongly depending on the respective soil layer, initialization season, and state. For RootSM the interquartile range of $\tau_{0}$ varies between 0.5 and 2 months for March and between 0.65 and 3.5 months for December. Single grid cells (99th percentile) for all seasons show a memory of up to 10 months. The memory for soil layer moisture increases with depth. The top layer only reaches median values of about 1 week although for individual grid cells the perturbation signal can be visible for up to 4 months (June and December). The median $\tau_{0}$ increases to about 5 months in the fifth layer while the interquartile range increases exponentially. Thus, a large ratio of grid cells is still affected by the perturbation after three seasons in the fourth layer and even after 2 years in the fifth layer. Down to the third layer, the longest $\tau_{0}$ is found for December initialization shifting to September for deeper layers. 


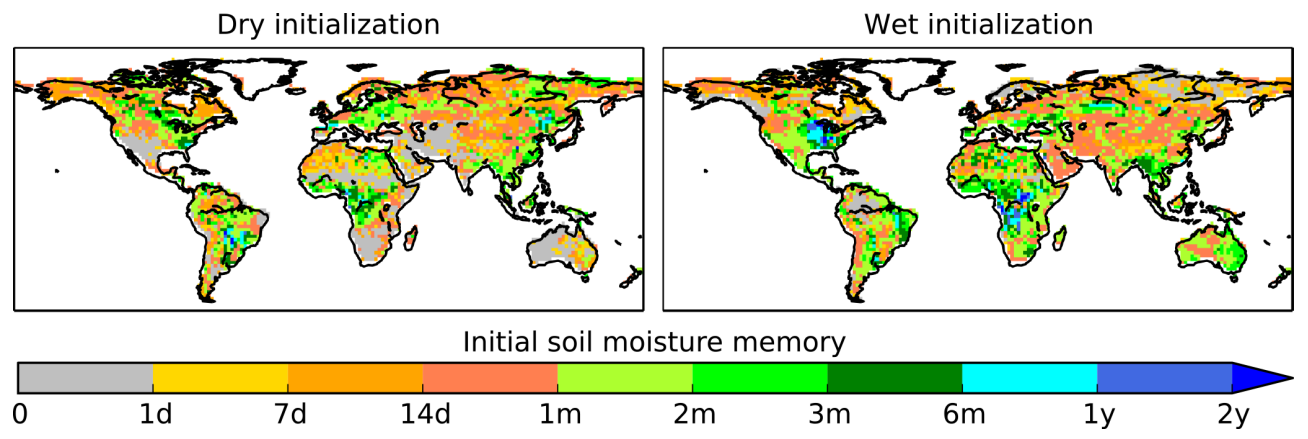

Figure 4. $\tau_{0}$ for RootSM in dry (left) and wet (right) initialized simulations. The letters $\mathrm{d}$, m, and y indicate days, months, and years, respectively.

For the RootSM and the upper three layers wet initializations correspond to a slightly longer $\tau_{0}$ than dry ones, but for lower layers dry perturbations become much more persistent.

The spatial pattern of the RootSM $\tau_{0}$ is investigated first by dividing the simulations into two (dry and wet initialized) ensembles (see Fig. 4) including all different seasons. A similar large-scale pattern can be found for both initialization states, indicating a generally higher sensitivity for soil moisture perturbations in some parts of the world. A short memory of between 2 and 4 weeks is evident for larger parts of Asia, central Australia and northwestern North America. Regions with a medium memory of between 1 and 6 months are found for the eastern USA, central and eastern South America, most of Europe, central Africa, and southeastern Asia. However, there are distinct differences for the more extreme values. A long memory of up to 1 year and more is found for wet initialization in the Congo region and the eastern USA, while it is much more sparse for dry initialization with two spots south of the Amazon catchment and in northeastern China. In return, areas without any memory are more common for dry than for wet initializations. While wet initialization shows no memory for parts of the high northern latitudes as well as the Amazon basin, dry anomalies cannot persist for the southwestern USA, the Sahel zone, South Africa, the Arabian peninsula, southeastern Asia, and western Australia. These regions coincide very well with dry conditions. There, dry perturbations have the lowest impact as the soils are usually in a dry state anyway. Thus, the perturbations are relatively small and fall within the climate variability. Wet perturbations are much larger and can result in $\tau_{0}$ of several months.

In a second step, the simulations were sorted with respect to the initialization season but not separated according to wet and dry initial perturbations. As already indicated by Fig. 3 , the resulting $\tau_{0}$ distributions show much more variance between seasons than between wet and dry initialization (see Fig. 5). The most prominent features are found for the Northern Hemisphere. For most parts of the high northern latitudes and central Asia, $\tau_{0}$ is shorter than 1 month for March to September initializations. However, with the on- set of the boreal winter, $\tau_{0}$ becomes much more persistent and reaches values of up to 6 months and more. This pattern seems to be related to the regional climate conditions. For March to September, the initialization often precedes periods of higher soil moisture variability. Thus, the computed initial states for the simulations are relatively small compared to the variability of the following season, and the perturbation signal decays fast. In contrast, the initial December states are still impacted by the summer soil moisture variability resulting in a large perturbation, which by far exceeds the moisture variability during winter. This perturbation is then conserved by the snow cover on the soil which hampers the exchange of water and energy between land and atmosphere. Thus, the initial perturbations can persist until next year's snowmelt. Another prominent feature are some regions along a band reaching from the African west coast towards India and then following the Asian coast in a northeasterly direction. In the September ensemble, they show a memory of up to 1 year. Almost the same regions are associated with 3 and 6 months shorter memory in the December and March ensembles, respectively, and this memory shortens to less than 2 weeks in the June ensemble. Similar behaviour is visible for South Africa, starting with the March ensemble, and South America starting with the June ensemble, although the latter shows a shorter memory of $\tau_{0} \leq 6$ months. Most of those regions closely resemble areas impacted by monsoon circulation as outlined by Lin et al. (2014). Monsoon periods are characterized by heavy precipitation during one season, which amounts to over $50 \%$ of the annual precipitation. Such precipitation results in a very high soil moisture content that completely removes all memory of previous wet or dry anomalies. However, in the seasons after monsoon, precipitation is much lower, resulting in low soil moisture variability and longer persistence of anomalies. This is well reflected in the derived memory distribution. For the Northern Hemisphere, monsoon usually occurs during the summer season; thus, almost no memory is seen in the June ensemble for western Africa and India. The next season (September ensemble) shows the longest memory of about 9 months that lasts until the next monsoon period, while every follow- 
March initialization

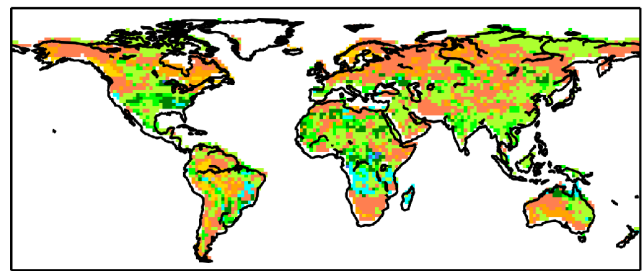

September initialization

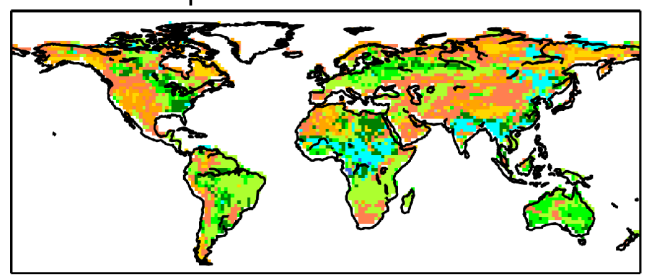

Initial soil moisture memory

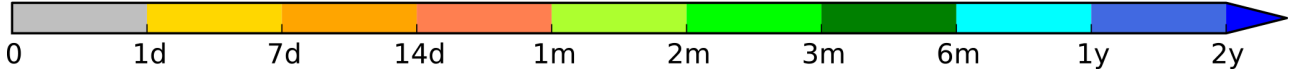

Figure 5. Ensemble mean $\tau_{0}$ for all (dry and wet) simulations initialized in a given season.

ing seasonal ensemble has a memory of 3 months less than the previous one. The same reasoning holds for the Southern Hemisphere. There the South African monsoon lasts from November till March, resulting in no memory for the December ensemble. The South American monsoon often lasts even longer, until April, resulting in a short memory for the December and March ensemble as well as a respective cut in the long memory evident in the June ensemble. This analysis reveals that not only the initialization state (e.g. wet versus dry) but also the time of initialization has a large impact on the resulting memory. This connection between precipitation variability and soil moisture memory is also in a more generalized form described in Koster and Suarez (2001) and Seneviratne and Koster (2012).

In order to identify more general systematics behind the spatial $\tau_{0}$ distribution, regions of similar soil moisture regimes were defined using the classification described in Seneviratne et al. (2010). The regimes are computed from REF climatology for all four seasons based on the state of soil moisture $\theta$ in relation to the wilting point $\theta_{\text {wilt }}$, below which no transpiration may occur, and the critical soil moisture $\theta_{\text {crit }}$, above which transpiration occurs at the potential rate and is not limited by soil moisture anymore. The regimes are classified into dry ( $\left.\theta \leq \theta_{\text {wilt }}\right)$, wet $\left(\theta \geq \theta_{\text {crit }}\right)$, and transitional ( $\theta_{\text {wilt }}<\theta<\theta_{\text {crit }}$ ) regimes (see Fig. 6). The grid cells are not distributed equally between the regimes. Instead, grid cells in transitional regimes exceed those in others by a factor of 5 (wet cells) to 20 (dry cells).

In spite of the strong differences in sample size, the partition into the three soil moisture regimes appears to be reasonable as they show distinctively different characteristics of soil moisture $\tau_{0}$ (see Fig. 7). For all seasons, the longest $\tau_{0}$ is found in dry regimes and the shortest $\tau_{0}$ in

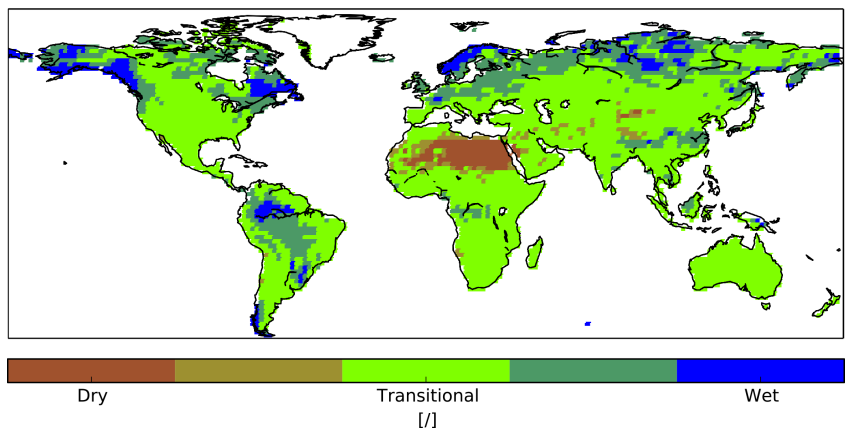

Figure 6. Soil moisture regimes based on REF climatology. Transient colours mark grid cells switching between the transitional and wet/dry regimes seasonally while the others remain in their category for the whole year.

wet regimes. While the dry and wet distributions within the regimes are quite symmetric for the March ensemble, the other ensembles show longer memory for wet perturbations in dry regimes, a symmetric shape for the transitional regime, and longer memory for dry perturbations in wet regimes. In contrast to the memory distribution, the $\Delta \theta_{0}$ distributions show a different relation to the soil moisture regimes. There, the smallest perturbations are evident for dry regimes and the largest for the transitional regimes for all seasons (not shown). This already indicates that the size of the initial perturbation cannot be the dominant driver for the initial soil moisture memory. This is confirmed by analysing the spatial correlation between soil moisture $\tau_{0}$ and $\Delta \theta_{0}$ for the different regimes and seasons as shown in Fig. 8 (lower panel). The correlations differ for the regimes as well as for seasons and show highest values of up to \pm 0.7 for June and September in the transitional regime. Similarly high values are found 

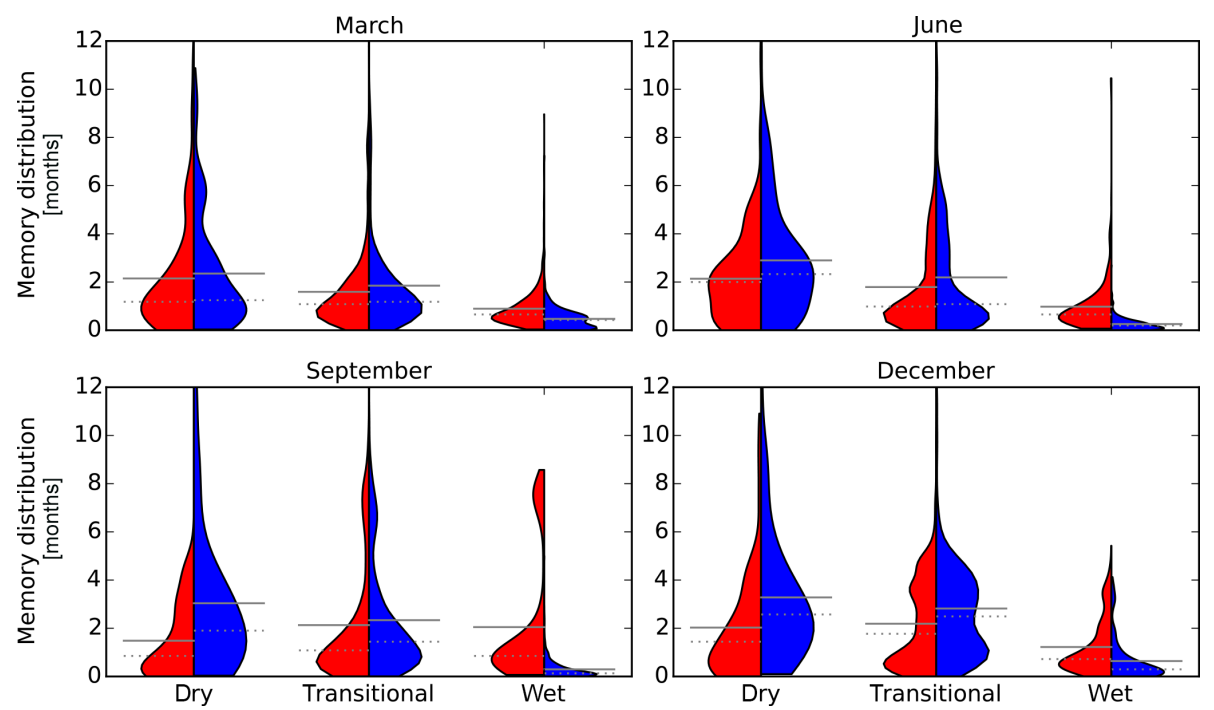

Figure 7. Violin plots of $\tau_{0}$ distribution for dry (red) and wet (blue) initialization in the three soil moisture regimes for the four seasonal ensembles. The horizontal grey lines indicate the mean (solid) and the median (dashed) of the distributions. All land surface grid cells of a given regime are included.
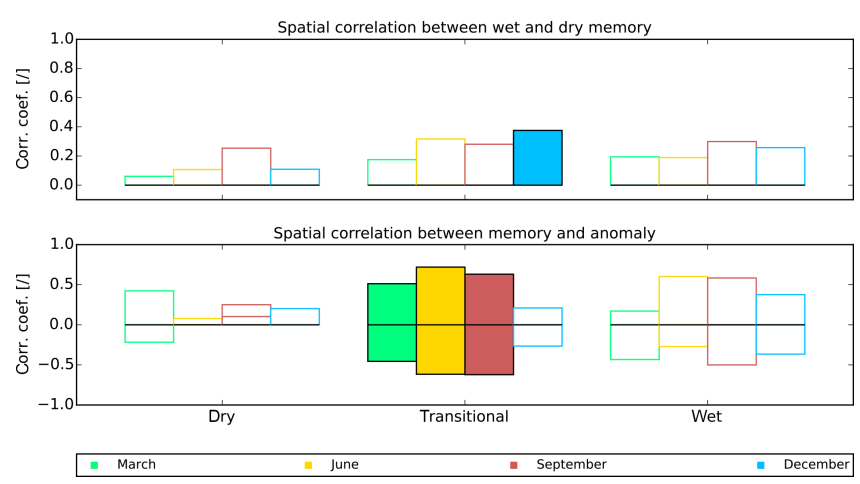

Figure 8. Bar plot for different soil moisture regimes and seasons, indicating correlation coefficients for spatial rank correlations. The upper panel shows the correlation between the pattern of wet $\tau_{0}$ and dry $\tau_{0}$. The lower panel shows the correlation between the pattern of wet and dry $\tau_{0}$ and the respective $\Delta \theta_{0}$. Significant correlations below the $5 \%$ level are indicated by solid bars.

for June and September in the wet regime, although there they are not significant $(p>5 \%)$. Thus, at most $50 \%$ of the spatial variance in memory pattern can be explained by the size of the initial perturbations. Furthermore, correlations between wet and dry memory are even lower with maximum values of 0.4 in the December ensemble for the transitional regime and no significant correlations for the other seasons and regimes at all (Fig. 8, upper panel). This indicates that for a given time step and grid cell, the soil might be susceptible to either wet or dry perturbations but rarely for both. Thus, the strength of soil moisture memory seems to depend about equally on the initial soil moisture perturbation as well as on dynamically changing land-atmosphere interactions and static soil or land cover properties.

In order to verify whether the next largest impact is due to static soil and land properties or due to seasonal climate dynamics, the spatial correlations between soil moisture $\tau_{0}$ and surface properties are computed (see Tables 1-4). The investigated parameters are related to surface properties (forest fraction, orographic standard deviation, maximum vegetation fraction), soil moisture state thresholds (maximum soil water capacity, rooting depth, soil depth until bedrock), and parameters determining water movement within the soil column (Clapp and Hornberger exponent, saturated hydraulic conductivity, saturated matrix potential, soil pore size distribution index, volumetric soil field capacity, volumetric soil porosity, volumetric wilting point). For most parameters correlations are low, varying between -0.25 and 0.25 during most seasons and are rarely significant. In particular for wet and dry soil moisture regimes as well as for the December ensemble in all regimes, no significant spatial correlations exist at all.

For the transitional regime, the strongest correlations are found for maximum soil water capacity and rooting depth ranging between 0.4 and 0.6 in the March to September ensembles. Since these seasons coincide with the seasons of high memory-perturbation correlation (see Fig. 8), it can be assumed that the higher rooting depth and maximum soil water capacity allow for larger perturbations that cause a longer memory. For the June ensemble, weak but significant correlations are also seen for the soil depth until bedrock. This is probably related to the rooting depth and soil water capacity correlations, as deep soils are often associated with a thicker root zone. Furthermore, a significant correlation is 
Table 1. Spatial March ensemble rank correlation coefficients between soil moisture $\tau_{0}$ and static soil properties for different soil moisture regimes and initializations. Bold font indicates significant correlation $(p<0.05)$.

\begin{tabular}{|c|c|c|c|c|c|c|}
\hline & \multicolumn{3}{|c|}{ Dry initialization } & \multicolumn{3}{|c|}{ Wet initialization } \\
\hline & dry & trans. & wet & dry & trans. & wet \\
\hline Clapp and Hornberger exponent $b$ & -0.08 & 0.23 & 0.2 & -0.05 & 0.16 & 0.1 \\
\hline Forest fraction & - & 0.16 & 0.03 & - & 0.11 & -0.3 \\
\hline Saturated hydraulic conductivity & 0.13 & -0.11 & -0.26 & 0.19 & 0.06 & -0.13 \\
\hline Maximum soil water capacity & 0.08 & 0.26 & 0.23 & 0.16 & 0.4 & -0.23 \\
\hline Saturated matrix potential & -0.13 & 0.17 & 0.25 & -0.18 & 0.03 & 0.11 \\
\hline Orographic standard deviation & -0.14 & -0.01 & -0.06 & 0.06 & 0.02 & 0.1 \\
\hline Soil pore size distribution index & 0.1 & -0.22 & -0.24 & 0.16 & -0.12 & -0.11 \\
\hline Rooting depth & 0.15 & 0.27 & 0.09 & 0.2 & 0.44 & -0.32 \\
\hline Soil depth until bedrock & 0.1 & 0.06 & -0.04 & -0.03 & 0.14 & -0.15 \\
\hline Volumetric soil field capacity & -0.11 & 0.07 & 0.23 & -0.16 & -0.05 & 0.12 \\
\hline Volumetric soil porosity & -0.13 & 0.04 & 0.22 & -0.18 & -0.1 & 0.17 \\
\hline Maximum vegetation fraction & -0.1 & 0.18 & 0.13 & 0.0 & 0.29 & -0.21 \\
\hline Volumetric wilting point & -0.1 & 0.14 & 0.23 & -0.14 & 0.02 & 0.12 \\
\hline
\end{tabular}

Table 2. Spatial June ensemble rank correlation coefficients between soil moisture $\tau_{0}$ and static soil properties for different soil moisture regimes and initializations. Bold font indicates significant correlation $(p<0.05)$.

\begin{tabular}{|c|c|c|c|c|c|c|}
\hline & \multicolumn{3}{|c|}{ Dry initialization } & \multicolumn{3}{|c|}{ Wet initialization } \\
\hline & dry & trans. & wet & dry & trans. & wet \\
\hline Clapp and Hornberger exponent $b$ & -0.13 & 0.19 & 0.11 & -0.17 & 0.12 & 0.06 \\
\hline Forest fraction & - & 0.36 & -0.02 & - & 0.07 & 0.05 \\
\hline Saturated hydraulic conductivity & -0.11 & -0.07 & -0.1 & -0.08 & 0.08 & -0.04 \\
\hline Maximum soil water capacity & 0.15 & 0.47 & 0.06 & 0.04 & 0.55 & 0.12 \\
\hline Saturated matrix potential & 0.05 & 0.12 & 0.05 & 0.03 & -0.02 & 0.05 \\
\hline Orographic standard deviation & -0.04 & -0.1 & -0.07 & -0.09 & -0.02 & 0.23 \\
\hline Soil pore size distribution index & -0.08 & -0.16 & -0.09 & -0.07 & -0.06 & -0.05 \\
\hline Rooting depth & 0.14 & 0.46 & -0.08 & 0.02 & 0.57 & 0.09 \\
\hline Soil depth until bedrock & 0.27 & 0.34 & 0.03 & 0.23 & 0.44 & 0.24 \\
\hline Volumetric soil field capacity & 0.06 & 0.1 & 0.08 & 0.08 & -0.05 & 0.07 \\
\hline Volumetric soil porosity & 0.07 & 0.05 & 0.09 & 0.05 & -0.13 & 0.05 \\
\hline Maximum vegetation fraction & 0.04 & 0.41 & -0.08 & -0.07 & 0.46 & 0.15 \\
\hline Volumetric wilting point & 0.03 & 0.13 & 0.11 & 0.05 & 0.0 & 0.05 \\
\hline
\end{tabular}

found for the forest fraction (0.35) with dry initialization and for the maximum vegetation fraction $(0.41-0.46)$ with both initializations. The forest fraction correlation is related to the generally deeper roots of trees compared to other plant types. The deep roots transpire water from a larger fraction of the soil column, effectively sustaining dry anomalies which in other grid cells are quickly compensated for by percolating water. In contrast, the correlation with the maximum vegetation fraction is significant for both wet and dry initializations. Here, the higher vegetation cover results in higher transpiration. We assume that depending on the location of the grid cells within the transitional soil moisture regime, increased transpiration can either sustain dry anomalies as it removes water from the soil column or, for regions where relative humidity is already high, the additional transpiration may trigger convection, resulting in additional precipitation, and therefore sustain the wet anomalies. However, it should be noted that positive soil moisture-precipitation feedback is considered to be rare in reality on the local scale (C. M. Taylor et al., 2012), and Guillod et al. (2015) also found that precipitation events tend to be located over drier patches. Still, those patches generally need to be surrounded by wet conditions (Guillod et al., 2015) so that positive temporal and spatial soil moisture-precipitation relationships are driven by large-scale soil moisture distribution. Additionally, positive soil moisture-precipitation feedback might be overestimated in the model due to its coarse resolution and the parametrization of convection (Hohenegger et al., 2009).

Together with the observed seasonal dynamics in soil moisture memory, these correlations demonstrate the limi- 
Table 3. Spatial September ensemble rank correlation coefficients between soil moisture $\tau_{0}$ and static soil properties for different soil moisture regimes and initializations. Bold font indicates significant correlation $(p<0.05)$.

\begin{tabular}{|c|c|c|c|c|c|c|}
\hline & \multicolumn{3}{|c|}{ Dry initialization } & \multicolumn{3}{|c|}{ Wet initialization } \\
\hline & dry & trans. & wet & dry & trans. & wet \\
\hline Clapp and Hornberger exponent $b$ & -0.04 & 0.18 & 0.18 & -0.16 & 0.07 & 0.09 \\
\hline Forest fraction & - & 0.35 & 0.07 & - & 0.23 & 0.04 \\
\hline Saturated hydraulic conductivity & -0.05 & -0.12 & -0.13 & 0.18 & 0.05 & -0.15 \\
\hline Maximum soil water capacity & 0.1 & 0.44 & 0.22 & 0.02 & 0.51 & 0.28 \\
\hline Saturated matrix potential & -0.0 & 0.13 & 0.07 & -0.17 & -0.01 & 0.11 \\
\hline Orographic standard deviation & 0.1 & -0.22 & -0.27 & -0.02 & -0.24 & -0.05 \\
\hline Soil pore size distribution index & -0.05 & -0.15 & -0.16 & 0.19 & -0.04 & -0.09 \\
\hline Rooting depth & 0.13 & 0.42 & 0.08 & 0.14 & 0.53 & 0.15 \\
\hline Soil depth until bedrock & 0.09 & 0.17 & 0.05 & 0.07 & 0.31 & 0.26 \\
\hline Volumetric soil field capacity & 0.03 & 0.15 & 0.13 & -0.17 & -0.04 & 0.18 \\
\hline Volumetric soil porosity & 0.04 & 0.12 & 0.12 & -0.19 & -0.08 & 0.17 \\
\hline Maximum vegetation fraction & -0.01 & 0.28 & -0.0 & -0.1 & 0.39 & 0.14 \\
\hline Volumetric wilting point & 0.01 & 0.17 & 0.21 & -0.16 & -0.01 & 0.15 \\
\hline
\end{tabular}

Table 4. Spatial December ensemble rank correlation coefficients between soil moisture $\tau_{0}$ and static soil properties for different soil moisture regimes and initializations. Note that all correlations during this season are insignificant $(p>0.05)$.

\begin{tabular}{|c|c|c|c|c|c|c|}
\hline & \multicolumn{3}{|c|}{ Dry initialization } & \multicolumn{3}{|c|}{ Wet initialization } \\
\hline & dry & trans. & wet & dry & trans. & wet \\
\hline Clapp and Hornberger exponent $b$ & -0.15 & 0.18 & 0.13 & 0.04 & 0.15 & 0.27 \\
\hline Forest fraction & - & 0.18 & 0.18 & - & 0.04 & -0.3 \\
\hline Saturated hydraulic conductivity & -0.04 & -0.27 & -0.1 & -0.02 & -0.12 & -0.34 \\
\hline Maximum soil water capacity & 0.06 & 0.02 & 0.24 & 0.09 & 0.17 & 0.02 \\
\hline Saturated matrix potential & 0.03 & 0.24 & 0.07 & 0.03 & 0.14 & 0.33 \\
\hline Orographic standard deviation & -0.14 & -0.07 & -0.13 & -0.06 & 0.01 & 0.02 \\
\hline Soil pore size distribution index & -0.03 & -0.22 & -0.1 & -0.01 & -0.15 & -0.3 \\
\hline Rooting depth & 0.07 & -0.02 & 0.08 & 0.13 & 0.16 & -0.24 \\
\hline Soil depth until bedrock & 0.1 & -0.2 & 0.07 & -0.03 & -0.1 & -0.02 \\
\hline Volumetric soil field capacity & 0.02 & 0.21 & 0.13 & 0.02 & 0.1 & 0.29 \\
\hline Volumetric soil porosity & 0.04 & 0.24 & 0.14 & 0.02 & 0.1 & 0.32 \\
\hline Maximum vegetation fraction & -0.06 & 0.01 & 0.18 & 0.07 & 0.17 & -0.0 \\
\hline Volumetric wilting point & - & 0.22 & 0.14 & 0.04 & 0.11 & 0.3 \\
\hline
\end{tabular}

tations in explaining soil moisture memory with static soil properties alone. Instead, the contribution of favourable climate states together with the size of the initial perturbation appear to be much more important for the formation of persistent anomalies.

\section{Interaction of perturbations between soil moisture and other state variables}

As already pointed out in earlier studies (Seneviratne et al., 2006; Rowntree and Bolton, 1983; and others), soil moisture anomalies also lead to alterations in other - originally not perturbed - state variables due to feedback mechanisms (see Sect. 1). However, it is not yet clear to what extent the memory within a state variable is affected by such feedbacks.
While assuming that memory is a specific characteristic for a given state, the overall memory of a coupled system of interacting states might differ distinctly from the sum of its parts. For this reason, the induced anomaly and memory statistics in other land surface states are analysed in the following.

The largest impact of soil moisture perturbations is expected for surface and soil temperatures due to the tight coupling of water and energy fluxes via the latent heatevapotranspiration flux. Indeed, induced perturbations are evident there (Fig. 9, left). The $\Delta \theta_{0}$ values are largest for the surface and top layer, with median values of $1.1 \mathrm{~K}(-1.4 \mathrm{~K})$ for dry (wet) initialization, which decrease towards 0 in the deepest layer. The extremes range between -10 and $9.5 \mathrm{~K}$ for the surface and still reach $\pm 0.5 \mathrm{~K}$ near the bottom of the soil column. While the interquartile range of the anomaly is 

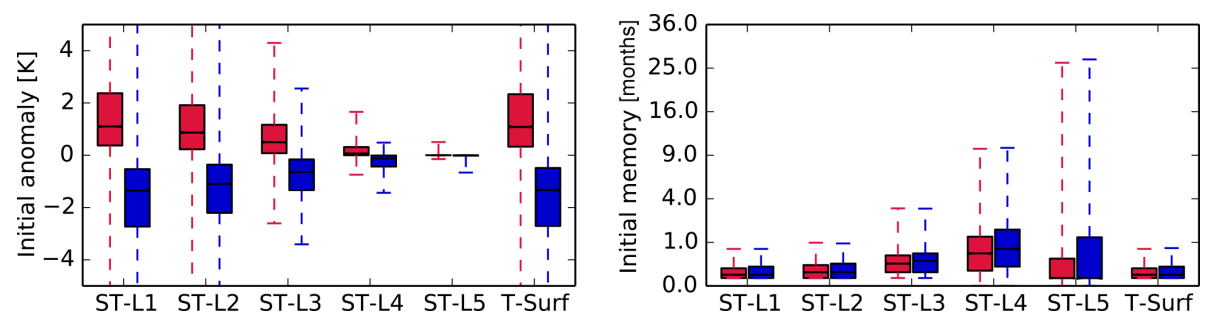

Figure 9. Global statistics for $\Delta \theta_{0}$ (left) and $\tau_{0}$ (right) in soil layer (ST-L1-5) and surface temperatures (T-Surf) in the wet (blue) and dry (red) initialized ensemble simulations for all land surface grid cells. The whiskers indicate the 1st and 99th percentiles, the box indicates the interquartile range, and the notch indicates the median. Note the quadratic axis for the memory statistics.
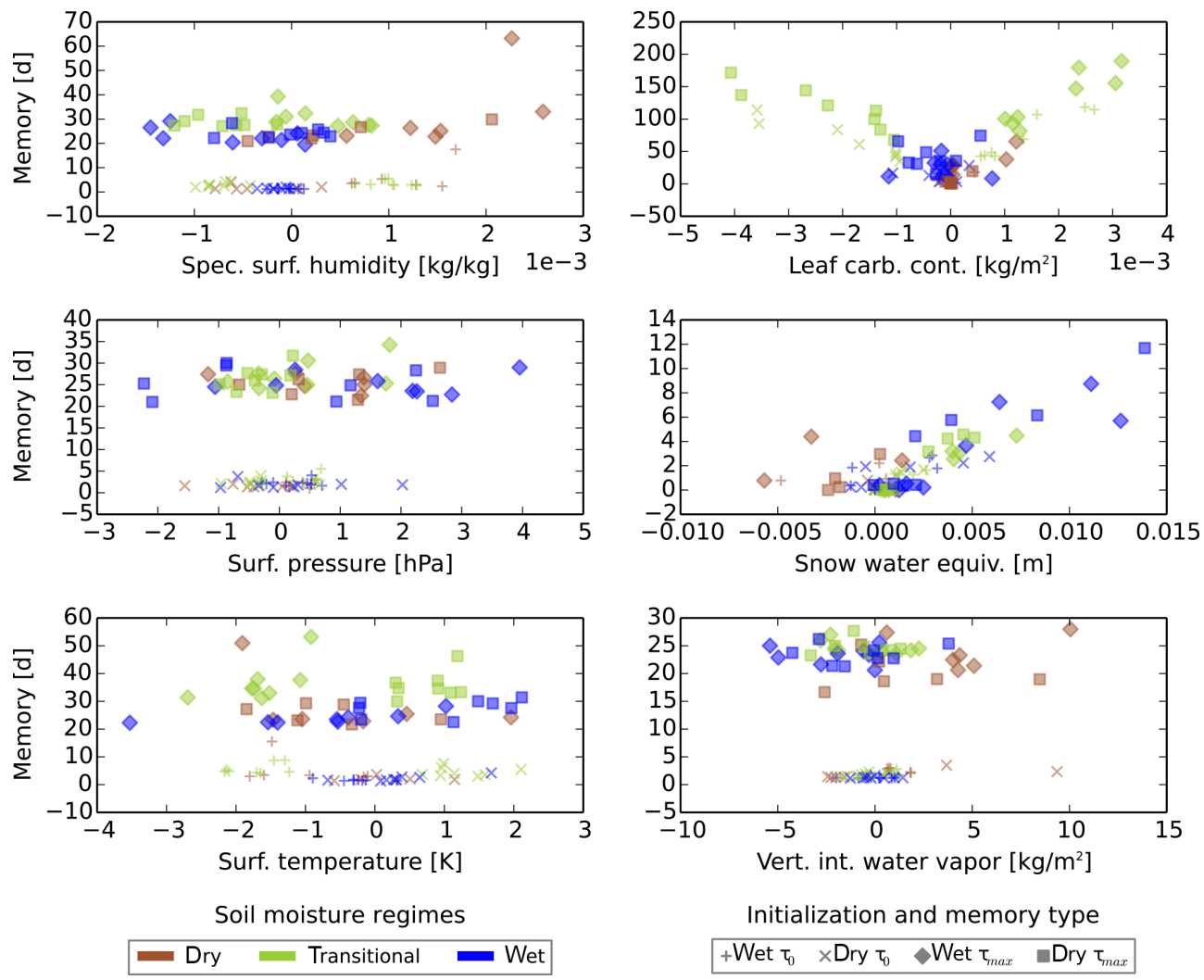

Initialization and memory type
+ Wet $\tau_{0} \quad \times$ Dry $\tau_{0} \quad$ Wet $\tau_{\max } \quad$ Dry $\tau_{\max }$

Figure 10. Scatter plots of induced anomaly-memory relation in surface states for all land surface grid cells. The colours indicate the soil moisture regime. The symbols refer to the soil moisture initialization state and the memory metric.

consistent with the initial soil moisture perturbation for all layers, e.g. warm anomalies for dry initialization and cold anomalies for wet initialization, extreme values with opposite anomalies exist. The memory in soil layer temperature is much shorter than for moisture. Starting from few a days at the surface, the median $\tau_{0}$ and its interquartile range increase with increasing depth towards a median of about 0.5 months in the fourth layer (Fig. 9, right). In the fifth layer, the value decreases again as a large fraction of the grid cells does not show any initial memory. The extremes, however, increase exponentially from 3 weeks at the surface to over 2 years in the lowest layer. Wet and dry initialized ensembles behave similar to each other; however, the interquartile range for the fourth and fifth layer is respectively about 0.5 and 1 months longer for wet initializations than for dry.

Induced perturbations are not only evident for surface and soil temperature but also occur in other land surface variables. Concerning the initial memory period (see Fig. 10, crosses and plus symbols) induced perturbations result in anomalies in the range of $\pm 1 \mathrm{hPa}$ for surface pressure, $\pm 0.005 \mathrm{~m}$ for snow water equivalent, -0.001 to $0.002 \mathrm{~kg} \mathrm{~m}^{-2}$ for specific surface humidity, -2.5 to $9.5 \mathrm{~kg} \mathrm{~m}^{-2}$ for vertically integrated water vapour, and $\pm 0.003 \mathrm{~kg} \mathrm{~m}^{-2}$ for the leaf carbon content (see Table 5 for details). However, the $\tau_{0}$ associated with these anomalies is rather short for all states but leaf carbon content where $\tau_{0}$ 
Table 5. Range of area-weighted mean values of $\Delta \theta_{0}$ (upper part) and $\Delta \theta_{\max }$ (lower part) for different soil moisture regimes and initializations. The semicolon separates minimum and maximum values occurring for different seasons and hemispheres.

\begin{tabular}{|c|c|c|c|c|c|c|}
\hline & \multicolumn{2}{|c|}{ Dry regime } & \multicolumn{2}{|c|}{ Transitional regime } & \multicolumn{2}{|c|}{ Wet regime } \\
\hline & Dry & Wet & Dry & Wet & Dry & Wet \\
\hline Leaf carbon $\left(\mathrm{kg} \mathrm{m}^{-2}\right)$ & $\begin{array}{c}-2.5 \times 10^{-4} \\
1.8 \times 10^{-5}\end{array}$ & $\begin{array}{l}8.7 \times 10^{6} \\
4.5 \times 10^{-4}\end{array}$ & $\begin{array}{l}-3.6 \times 10^{-3} \\
-9.4 \times 10^{-4}\end{array}$ & $\begin{array}{l}5.6 \times 10^{-4} ; \\
42.7 \times 10^{-3}\end{array}$ & $\begin{array}{c}-1.1 \times 10^{-3} \\
3.4 \times 10^{-4}\end{array}$ & $\begin{array}{c}-2.5 \times 10^{-4} \\
9.4 \times 10^{-5}\end{array}$ \\
\hline Surf. pressure $(\mathrm{hPa})$ & $\begin{array}{c}-1.56 \\
0.21\end{array}$ & $\begin{array}{c}0.11 \\
0.59\end{array}$ & $\begin{array}{c}-0.96 \\
0.66\end{array}$ & $\begin{array}{c}-0.29 \\
0.69\end{array}$ & $\begin{array}{c}-0.97 \\
2.03\end{array}$ & $\begin{array}{c}-0.30 \\
0.70\end{array}$ \\
\hline Snow cover $(\mathrm{m})$ & $\begin{array}{c}-3.9 \times 10^{-4} \\
0.0\end{array}$ & $\begin{array}{c}-4.8 \times 10^{-3} \\
5.7 \times 10^{-4}\end{array}$ & $\begin{array}{c}-2.9 \times 10^{-5} \\
2.5 \times 10^{-3}\end{array}$ & $\begin{array}{c}0.0 \\
2.6 \times 10^{-3}\end{array}$ & $\begin{array}{c}-1.3 \times 10^{-3} \\
5.9 \times 10^{-3}\end{array}$ & $\begin{array}{c}-1.2 \times 10^{-3} \\
3.2 \times 10^{-3}\end{array}$ \\
\hline Spec. surf. humidity $\left(\mathrm{kg} \mathrm{kg}^{-1}\right)$ & $\begin{array}{c}-7.9 \times 10^{-4} \\
3.1 \times 10^{-4}\end{array}$ & $\begin{array}{l}6.2 \times 10^{-4} \\
1.7 \times 10^{-3}\end{array}$ & $\begin{array}{l}-9.9 \times 10^{-4} \\
-4.2 \times 10^{-4}\end{array}$ & $\begin{array}{l}6.6 \times 10^{-4} \\
1.3 \times 10^{-3}\end{array}$ & $\begin{array}{c}-3.5 \times 10^{-4} \\
5.1 \times 10^{-5}\end{array}$ & $\begin{array}{c}-2.5 \times 10^{-4} \\
1.3 \times 10^{-4}\end{array}$ \\
\hline Atmosp. water vapour $\left(\mathrm{kg} \mathrm{m}^{-2}\right)$ & $\begin{array}{c}-2.43 \\
9.36\end{array}$ & $\begin{array}{l}0.62 \\
1.85\end{array}$ & $\begin{array}{l}-1.77 \\
-0.23\end{array}$ & $\begin{array}{c}0.48 \\
1.23\end{array}$ & $\begin{array}{c}-1.27 \\
1.43\end{array}$ & $\begin{array}{c}-1.99 ; 1.01 \\
1.01\end{array}$ \\
\hline Leaf carbon $\left(\mathrm{kg} \mathrm{m}^{-2}\right)$ & $\begin{array}{c}-9.3 \times 10^{-5} \\
4.0 \times 10^{-4}\end{array}$ & $\begin{array}{l}2.4 \times 10^{-5} \\
1.2 \times 10^{-3} \\
\end{array}$ & $\begin{array}{l}-4.1 \times 10^{-3} \\
-1.0 \times 10^{-3}\end{array}$ & $\begin{array}{l}1.0 \times 10^{-3} \\
3.2 \times 10^{-3}\end{array}$ & $\begin{array}{c}-9.7 \times 10^{-4} \\
5.5 \times 10^{-4}\end{array}$ & $\begin{array}{c}-1.1 \times 10^{-3} \\
7.7 \times 10^{-4}\end{array}$ \\
\hline Surf. pressure (hPa) & $\begin{array}{c}-0.66 \\
2.64\end{array}$ & $\begin{array}{c}-1.17 \\
1.40\end{array}$ & $\begin{array}{c}-0.98 \\
0.22\end{array}$ & $\begin{array}{c}-0.85 \\
1.81\end{array}$ & $\begin{array}{c}-2.23 \\
2.52\end{array}$ & $\begin{array}{c}-1.06 \\
3.95\end{array}$ \\
\hline Snow cover $(\mathrm{m})$ & $\begin{array}{c}-2.4 \times 10^{-3} \\
2.6 \times 10^{-4}\end{array}$ & $\begin{array}{c}-5.7 \times 10^{-3} \\
1.4 \times 10^{-3}\end{array}$ & $\begin{array}{l}4.0 \times 10^{-4} \\
5.1 \times 10^{-3}\end{array}$ & $\begin{array}{l}3.4 \times 10^{-4} \\
7.3 \times 10^{-3}\end{array}$ & $\begin{array}{c}-7.6 \times 10^{-5} \\
0.01\end{array}$ & $\begin{array}{c}2.3 \times 10^{-4} \\
0.01\end{array}$ \\
\hline Spec. surf. humidity $\left(\mathrm{kg} \mathrm{kg}^{-1}\right)$ & $\begin{array}{c}-4.5 \times 10^{-4} \\
2.1 \times 10^{-3}\end{array}$ & $\begin{array}{l}5.7 \times 10^{-4} \\
2.6 \times 10^{-3} \\
\end{array}$ & $\begin{array}{l}-1.2 \times 10^{-3} \\
-1.5 \times 10^{-4}\end{array}$ & $\begin{array}{c}-1.6 \times 10^{-4} \\
8.2 \times 10^{-4}\end{array}$ & $\begin{array}{c}-8.0 \times 10^{-4} \\
4.0 \times 10^{-4}\end{array}$ & $\begin{array}{c}-1.5 \times 10^{-3} \\
1.4 \times 10^{-4}\end{array}$ \\
\hline Atmosp. water vapour $\left(\mathrm{kg} \mathrm{m}^{-2}\right)$ & $\begin{array}{c}-2.59 \\
8.47\end{array}$ & $\begin{array}{c}0.60 ; 10.05 \\
10.05\end{array}$ & $\begin{array}{c}-3.30 \\
1.31\end{array}$ & $\begin{array}{c}-2.79 \\
2.26\end{array}$ & $\begin{array}{c}-4.25 \\
3.79\end{array}$ & $\begin{array}{c}-5.40 \\
0.22\end{array}$ \\
\hline
\end{tabular}

Table 6. Range of area-weighted mean values of $\tau_{0}$ (upper part) and $\tau_{\max }$ (lower part) in months for different soil moisture regimes and initializations. The semicolon separates minimum and maximum values occurring for different seasons and hemispheres.

\begin{tabular}{|c|c|c|c|c|c|c|}
\hline & \multicolumn{2}{|c|}{ Dry regime } & \multicolumn{2}{|c|}{ Transitional regime } & \multicolumn{2}{|c|}{ Wet regime } \\
\hline & Dry & Wet & Dry & Wet & Dry & Wet \\
\hline Leaf carbon & $0.02 ; 0.42$ & $0.05 ; 0.76$ & $1.14 ; 3.74$ & $1.39 ; 3.88$ & $0.12 ; 0.93$ & $0.06 ; 0.41$ \\
\hline Surf. pressure & $0.04 ; 0.07$ & $0.03 ; 0.10$ & $0.06 ; 0.13$ & $0.07 ; 0.18$ & $0.04 ; 0.12$ & $0.05 ; 0.13$ \\
\hline Snow cover & $0.0 ; 0.03$ & $1.6 \times 10^{-3} ; 0.07$ & $0.0 ; 0.06$ & $0.0 ; 0.05$ & $7.0 \times 10^{-3} ; 0.09$ & $0.0 ; 0.09$ \\
\hline Spec. surf. humidity & $0.04 ; 0.13$ & $0.08 ; 0.57$ & $0.06 ; 0.14$ & $0.09 ; 0.18$ & $0.04 ; 0.07$ & $0.04 ; 0.05$ \\
\hline Atmosp. water vapour & $0.04 ; 0.11$ & $0.07 ; 0.10$ & $0.05 ; 0.08$ & $0.05 ; 0.09$ & $0.04 ; 0.05$ & $0.04 ; 0.04$ \\
\hline Leaf carbon & $0.02 ; 0.65$ & $0.47 ; 2.14$ & $2.23 ; 5.63$ & $2.67 ; 6.21$ & $0.50 ; 2.44$ & $0.28 ; 1.67$ \\
\hline Surf. pressure & $0.71 ; 0.95$ & $0.74 ; 0.91$ & $0.76 ; 1.04$ & $0.79 ; 1.12$ & $0.69 ; 0.99$ & $0.75 ; 0.95$ \\
\hline Snow cover & $0.0 ; 0.10$ & $1.6 \times 10^{-3} ; 0.14$ & $0.0 ; 0.15$ & $0.0 ; 0.15$ & $0.01 ; 0.38$ & $0.0 ; 0.29$ \\
\hline Spec. surf. humidity & $0.69 ; 0.98$ & $0.75 ; 2.07$ & $0.89 ; 1.06$ & $0.89 ; 1.29$ & $0.73 ; 0.93$ & $0.64 ; 0.96$ \\
\hline Atmosp. water vapour & $0.55 ; 0.83$ & $0.68 ; 0.92$ & $0.76 ; 0.91$ & $0.77 ; 0.88$ & $0.70 ; 0.86$ & $0.68 ; 0.84$ \\
\hline
\end{tabular}

lasts for up to 4 months (see Table 6). In order to identify a systematic behaviour in these effects, the anomaly-memory relations are divided into wet and dry initializations. It becomes visible that the dry and wet perturbations in dry and transitional soil moisture regimes mostly result in either positive or negative anomalies. For the wet soil moisture regime, however, positive as well as negative anomalies are visible for any perturbation. The $\tau_{0}$ does not seem to be related to the $\Delta \theta_{0}$ for any state but leaf carbon content. Here the largest anomalies correspond to the longest memory and occur in the transitional regime, while both dry and wet regimes show shorter memory and smaller anomalies. For the dry regime this is probably due to the low amount of plant cover, whereas in the wet regime, there is no water limitation and therefore leaf carbon content becomes insensitive to variations in soil moisture.

Taking into account the full time series (Fig. 10, filled symbols), the change in memory indicates that there are not 

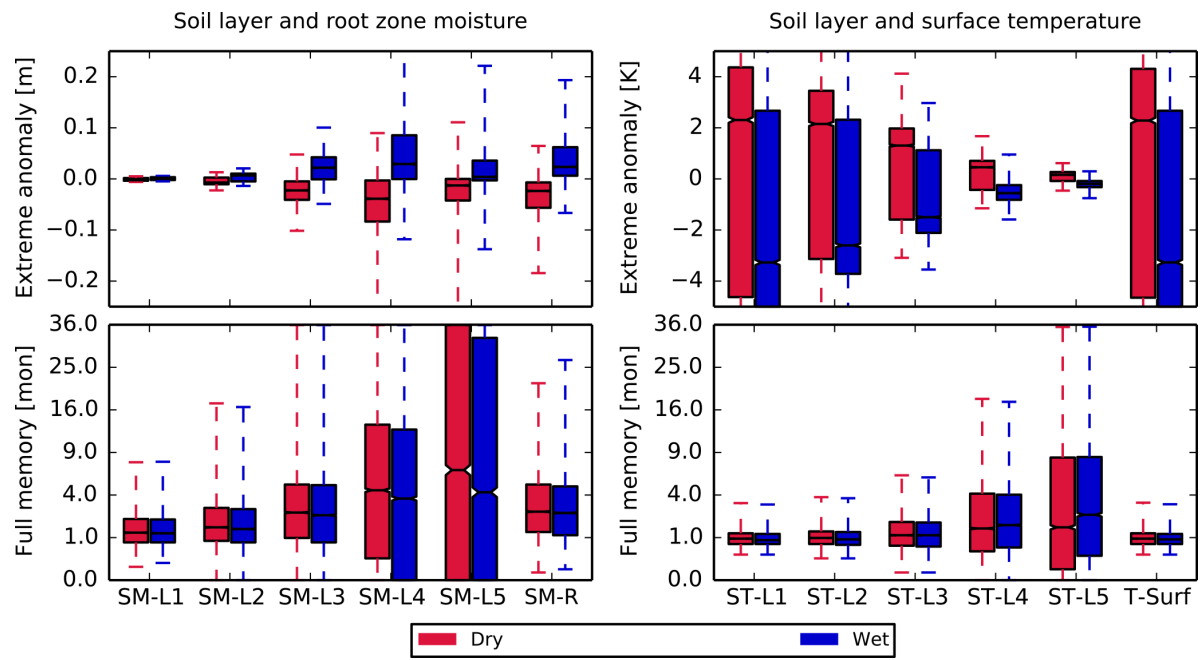

Figure 11. Global statistics for extreme anomalies $\Delta \theta_{\max }$ during the full time series (top panels) and accumulated memory $\tau_{\text {max }}$ (bottom panels) in soil layer moisture (left side) and temperature (right side) in the wet (blue) and dry (red) initialized ensemble simulations. All land surface grid cells are included.

only initial, induced perturbations with an associated memory but that anomalies recur again at later time steps. For some variables, these anomalies show even larger magnitudes than the initial ones. The accumulated memory $\tau_{\max }$ for most variables rises from a few days to about 1 month, and the memory for leaf carbon content doubles to 6 months. Snow water equivalent $\tau_{\max }$ stays low for around 1 week for all regime-initialization combinations as does the leaf carbon content $\tau_{\max }$ for dry perturbations in the dry soil moisture regime. While the sign of the anomalies corresponds to the expectations for some variables, e.g. wet initialization resulting in positive anomalies for leaf carbon content and negative anomalies for surface temperature and vice versa, other variables (snow cover, surface pressure) react with anomalies in both directions. More details on the overall memory and anomalies in soil moisture and temperature are displayed in Fig. 11 and are compared to the statistics of the initial perturbation and memory (see Fig. 3 for soil moisture and Fig. 9 for soil temperature) in the following discussion. For soil moisture, there are almost no differences between the magnitudes of $\Delta \theta_{0}$ and $\Delta \theta_{\max }$. Thus, anomalies during later memory periods are usually smaller than at the beginning, indicating that no positive feedbacks or new equilibria are triggered by the initial perturbations. However, $\tau_{\max }$ for all layers is increased by $1-1.5$ months for the median and up to 4 months for the 75 th percentile. The largest increase is visible for the upper extreme of RootSM memory with 15 months. Extreme anomalies for soil temperature behave similarly to initial anomalies and become smaller for deeper soil layers. Changes in magnitude range between -5 and $3 \mathrm{~K}$ for the surface and vary around $\pm 0.3 \mathrm{~K}$ in the deep layers. The separation between positive and negative anomalies in response to the initial soil moisture perturbation is not as dis- tinct anymore for the upper three layers. The accumulated median memory is at least 1 month for all layers, and the interquartile range as well as extremes increase even more strongly than for the initial memory. For the 75 th percentile, $\tau_{\max }$ exceeds $\tau_{0}$ by 1 (8) month for the first (fifth) layer. The differences between wet and dry initialization are less extreme compared to $\tau_{0}$ statistics but still a slightly longer memory is found for wet initialization in the lowest layer.

These analyses demonstrate that memory occurrence and anomaly recurrence are not limited to soil moisture and the closely linked soil temperature. Instead, the soil moisture perturbations affect most of the land surface system although to a different extent. However, the mechanism responsible for the recurrence of anomalies in the different variables cannot be identified from these analyses.

\section{Anomaly interaction pathways between state variables}

In technical terms, the recurrence of state variable anomalies indicates that the anomaly mean and the anomaly standard deviation for a given location are not just two steadily decreasing and increasing curves at whose intersection the memory ends. Instead one or both of them show temporal variations which result in the anomaly becoming visible $(\mathrm{SNR} \geq 1)$ again. In the following, this possible recurrence is explored on a grid cell level by investigating the SNR time series relationship (see Eq. 1) between different state variables. Here, we focus on leaf carbon content and (deeplayer) soil temperature as the longest accumulated memory was computed for these variables. In order to find suitable grid cells for the analysis, we applied a number of conditions, namely the difference between $\tau_{\max }$ and $\tau_{0}$ being $>600$ days 
and the amount of recurring memory periods $\geq 3$. Only such grid cells were analysed that comply with these conditions. Additionally, they were ranked according to the similarity between the length of their memory periods as we expect more robust results for regularly recurring anomalies.

For all state variables except soil moisture, the anomaly recurrence is simple to explain. For example, soil moisture perturbations affect leaf carbon content and can result in anomalies with a distinct memory (see Sect. 4). However, leaf carbon content follows a yearly cycle and can become insensitive to soil moisture anomalies during certain time periods, i.e. when soil moisture is below the wilting point or above the critical soil moisture. The latter case occurs for the leaf carbon content shown in Fig. 12 (right). Here, the anomaly vanishes during periods of maximum leaf carbon in the reference simulation. If the soil moisture perturbation still exists after the peak, a new anomaly is triggered and leaf carbon memory recurs. A connection between the memory pattern of soil moisture and vegetation is also proposed by an observationbased study by Shinoda and Nandintsetseg (2011). Similarly, soil temperature anomalies do not depend on soil moisture anomalies alone but also on evapotranspiration anomalies. These are only triggered when several climate conditions (e.g. downward radiation, surface humidity) are favourable (not shown). Thus, temperature anomalies emerge as long as these conditions apply but, as surface temperature memory is short, are interrupted whenever the favourable conditions fade. In both cases, the recurrence of state memory is possible only because soil moisture memory lasts long enough until conditions for anomalies become favourable again.

As there is no state variable that demonstrated a longer memory than soil moisture, another explanation is needed for its memory recurrence. Still, there are several possible explanations for this phenomenon: the first hypothesis is based on feedbacks between different state variables. As shown in the previous section soil moisture perturbations induce anomalies in other variables. However, the induction may have a certain lag time and furthermore the memory of the anomalies differs between the various states. Thus, it would be possible that a soil moisture anomaly induces a temporally lagged anomaly in another state with a different memory. While the soil moisture anomaly is already decayed, the induced state anomaly might still exist and - if there is a feedback loop between both - induce a secondary anomaly in soil moisture. This effect would be visible as wave-like variations in the ensemble anomaly mean. Additionally, stored memory might already exist in other land surface variables such as snow cover or vegetation prior to the soil moisture perturbation and could amplify or mitigate the initial soil moisture memory using the same process chain. The second hypothesis is that the soil moisture anomalies might be stable over long time periods, but its memory could be temporally hidden during periods with pronounced variability in interacting variables. This would become visible as a rather steady and slow decline of the anomaly mean curve, which would be overlain by periodical increases in the ensemble anomaly standard deviation.

For soil moisture, the best example is found for a grid cell at $-2.8^{\circ} \mathrm{N}$ and $13.12^{\circ} \mathrm{E}$ (west Africa, Republic of Congo) during wet initialization in September. Its ensemble mean anomaly and SNR time series are shown in Fig. 13 for soil moisture and soil temperature in the different soil layers. At this location the depth of the bedrock is prescribed with $5.6 \mathrm{~m}$ while root depth extends down to 2.8 unitm. This means that the water content of the lowest soil moisture layer as well as of about $50 \%$ of the fourth layer is not directly accessible to plants for transpiration. Consequently, the SNR soil moisture curves (Fig. 13, right) exhibit very different temporal dynamics for the soil layers. In the upper three layers, which are within the root zone, the initialized perturbation decays within 1 (2) months for the first (third) layer. It recurs at yearly intervals for a 3-month period, although only the recurrence after 12 months shows memory for all three layers, while for later recurrences, SNR stays below 1. In between these intervals, the SNR curves are subject to highfrequency variations. The increasing length of memory and the less variable SNR signal reflect the increasing soil layer thickness with depth in these layers. The root zone moisture as a whole also reflects the yearly intervals of increased SNR but shows much less high-frequency variability. The SNR is above 1 for most of the time series. In contrast to the upper layers, the fourth and fifth layer, which represent the water reservoir below the root zone, show the slowly decaying SNR signal of the initial perturbation without any shortterm variability. Comparing the SNR curves to the anomaly time series (Fig. 13, left), the same slow decay is visible for the anomalies in the two lowest layers. Above, distinct wet anomalies mark the annual recurrence of memory while, in between, small wet and dry anomalies are visible. The intraannual anomalies usually show a small time lag for deeper layers indicating that the anomaly is migrating from the top layer into the deeper layers. However, the annual anomalies are already visible in the third layer before they start in the second or first one. Therefore, the wet anomalies could be related to water percolating downwards that is retained here due to the higher water content of the lower layers. Alternatively, it is even possible that water is migrating upwards via diffusion due to the positive water anomaly in the lower layers leading to an strengthened gradient between those layers. For the actual grid cell, the second case is more probable as the wet anomalies coincide with the minima of the REF precipitation climatology. Thus, the anomaly and memory recurrence within the RootSM results from interactions with the uninterrupted period of memory in the deep moisture layers below the root zone.

Additionally, the vertical profile of soil temperature memory is analysed for the same grid cell (Fig. 13, bottom). Similar to soil moisture memory, variability for soil temperature is higher for the thin top layers and lower for the thick, deep layers. Three events of increased memory are visible 


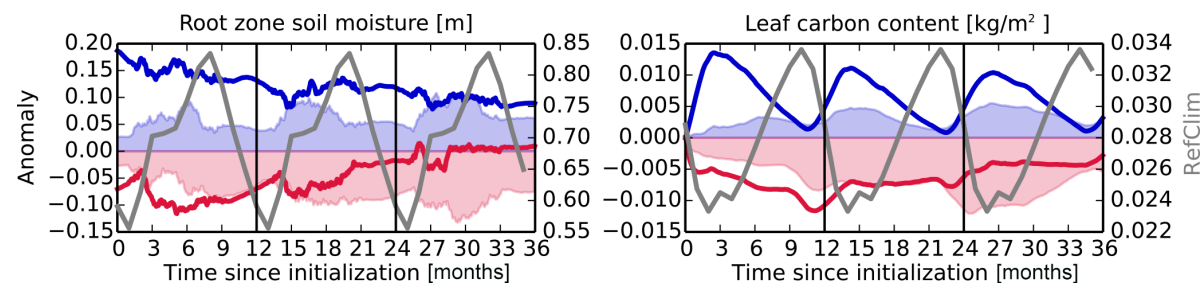

Figure 12. Ensemble mean anomaly (coloured lines) and standard deviation (shaded area) for root zone soil moisture (left) and carbon content in leaves (right) with the respective climatologies (grey) from the reference simulation. Blue colours indicate wet initialization and red colours indicate dry initialization. Time series are from a grid cell at $-2.8^{\circ} \mathrm{N}$ and $13.12^{\circ} \mathrm{E}$.

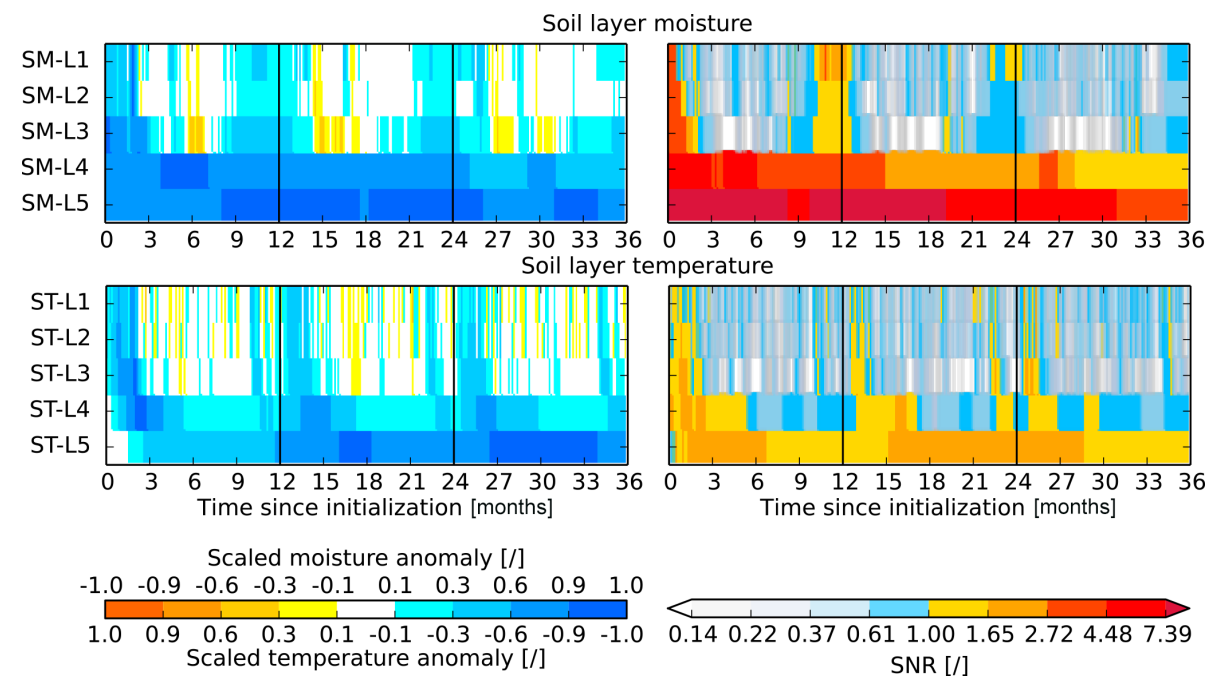

Figure 13. Time series of ensemble mean $\Delta \theta_{0}$ and SNR for a grid cell at $-2.8^{\circ} \mathrm{N}$ and $13.12^{\circ} \mathrm{E}$ (Republic of Congo) of the wet initialization September ensemble. The upper and lower panels show soil moisture and soil temperature, respectively, for all soil layers. The anomaly notation is mirrored for the soil temperature. Note, that the SNR colour spacing is logarithmic in order to display the ratio similar to a normal distribution. All yellow and red patches in the right panels indicate time periods defined as memory.

that correspond to the memory recurrence in soil moisture. Even though variability in the top layer is very high, a distinct downward movement of the memory signal is visible, starting with short periods of a few days in the topsoil layer. The downward movement shows a short time lag in memory occurrence for every layer together with a longer memory of the single events due to the increasing layer thickness. Additionally, the accumulation of anomaly and memory is visible in the lower two layers. Here, the vertical structure of the signal reflects the migration of the induced temperature anomalies from the top layer downwards. As the memory increases with depth and layer thickness, the rather short-lived anomalies of the top layer accumulate to a distinct and steady anomaly in the lower two layers. This top-down movement is not only supported by the pattern of the anomaly time series (Fig. 13, left) but follows from the model physics. In this version of JSBACH, phase changes in moisture within the ground are not considered and there is no interaction between moisture and temperature within the soil column. The only existing link between both is the latent heat flux or evapotranspiration at the soil surface. Thus, the first part of the hy- pothesized anomaly and memory transport between variables is realized here, as changes in RootSM induce anomalies and memory in the deep-layer soil temperatures. However, there is no feedback evident from the temperatures to the moisture state. Thus, in this experiment the recurring soil temperature anomalies are most likely caused by recurring soil moisture memory but not vice versa.

The grid cell analysis demonstrates the possibility of memory interactions between variables although no indication was found for a closed memory interaction loop that feeds back into soil moisture again. Instead, anomaly recurrence in RootSM seems to depend on the existence of deep-soil layers below the root zone. In order to conclude whether this is true for the model in general or just for the one grid cell, we divided all grid cells into three groups depending on the thickness of the soil column below the root zone. For these groups, the frequency distribution of memory recurrence was calculated for every soil moisture regime and is displayed in Fig. 14. Indeed the curves differ distinctively between grid cells without any deep-soil layers and grid cells with either thin $(\leq 1 \mathrm{~m})$ or thick deep-soil layers. It can be seen, that 


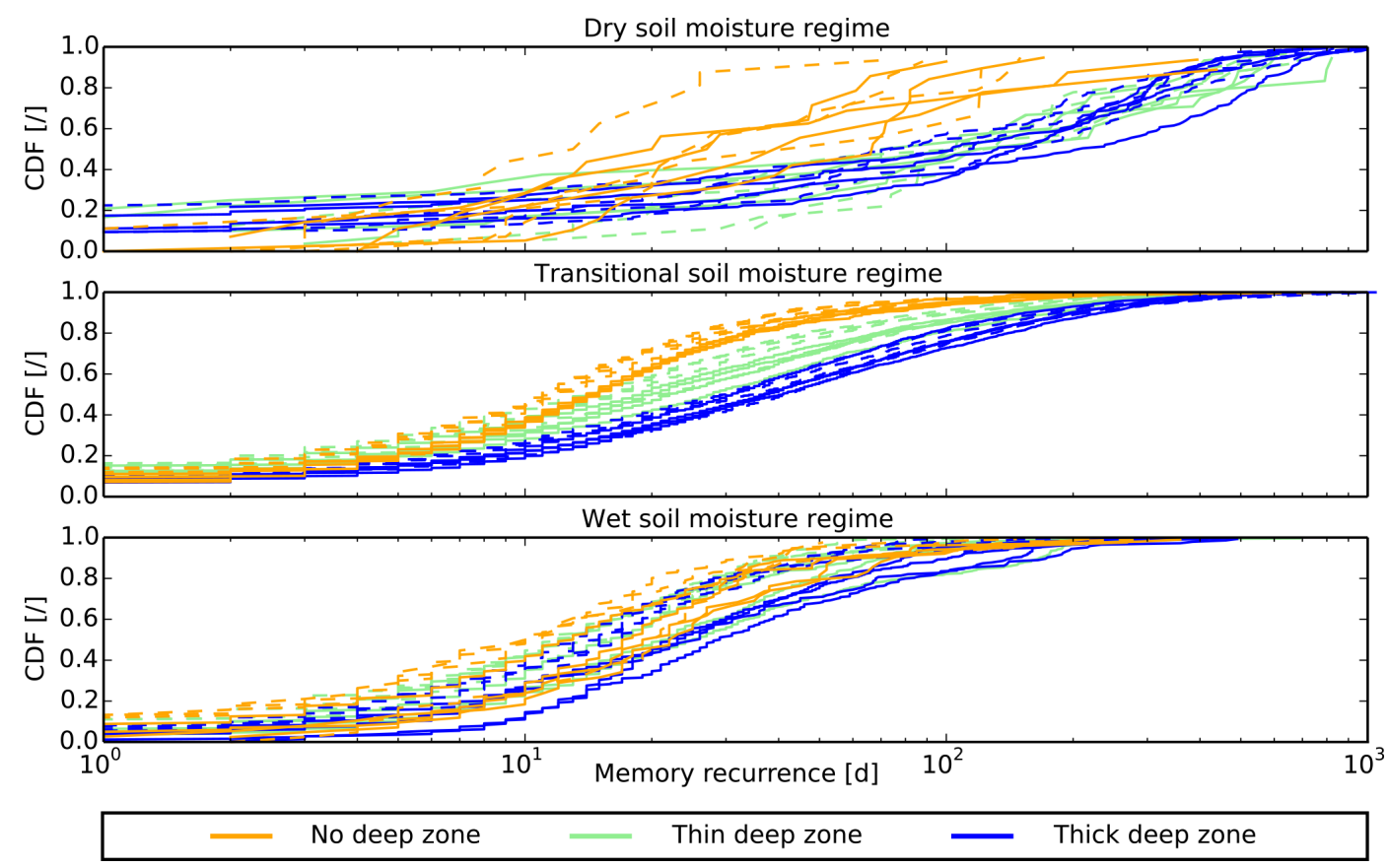

Figure 14. Normalized cumulative frequency of grid cells with recurring memory $\left(\tau_{\max }-\tau_{0}\right)$ for different soil moisture regimes (upper, middle, and lower panels). The regimes are further subdivided depending on the thickness of the deep-soil zone below the root zone (orange, green, and blue colours). Wet (dashed lines) and dry (solid lines) initial states and seasons are merged in the panels.

memory recurrence is generally more frequent for dry soil moisture regimes than for wet ones. Additionally, the impact of the deep-soil thickness is strongest for dry regimes and almost not visible for the wet regimes. The figure also shows the impact of different seasons and initializations on the memory recurrence. The seasonal variations are mostly not distinguishable, but the wet initialization shows systematically less memory recurrence than the dry initialization. For the transitional regime, the major part of the impact is seen for the recurrence range of 5-200 days where all three sets of deep-layer thickness are well separated. In the dry regime there are no differences between thin or thick deepsoil layers, but there is a large offset to the cells without any deep-soil layers. Consequently, the deep-soil moisture storage seems to play a prominent role for the memory characteristics within the RootSM in all but the wet soil moisture regime. Still, there is a significant part of the land surface where memory recurrence is caused by other processes, e.g. in the wet soil moisture regimes and all the grid cells without any deep-soil layers. There are indications that the second hypothesis, the steadily declining anomalies interrupted by periods of high variability, is realized as well. An example on grid cell scale is shown in Fig. 12 (left). Here the anomaly is above the mean level of ensemble standard deviation over the whole 3 years. It even increases periodically due to recharge from the deep-soil layer. However, during the rainy seasons, the ensemble standard deviation increases strongly and overlays the mean, thus dividing the memory signal into several separate periods. However, a more comprehensive analysis of this effect and other possible reasons for memory recurrence on a global scale is beyond the scope of this study as it would need a different experiment set-up.

\section{Summary}

The presented soil moisture initialization experiment was designed to reveal information about the lifetime of extreme yet realistic - soil moisture perturbations in a coupled climate model. For the root zone, those lifetimes range from days up to 1 year and, thus, are consistent with the range of memory found by other studies (e.g. Manabe and Delworth, 1990; Hagemann and Stacke, 2015; Ferranti and Viterbo, 2006).

The distribution of memory shows a systematic relation with soil moisture regimes and is consistent with large-scale physical characteristics. A prominent example is the soil moisture memory for monsoon regions, which is extremely low during the monsoon period as any soil moisture perturbations are negligible in face of the heavy precipitation. A similar result was reported by Seneviratne et al. (2006), who computed the global soil moisture autocorrelation pattern based on an ensemble of eight atmospheric general circulation models. Their simulations started in June and led to a memory pattern very similar to the pattern of the June ensemble in our study. However, memory in the period after the monsoon is among the longest found globally and lasts until the next year's monsoon season starts again. Thus, monsoon 
regions are actually regions of significant memory if considered after the main precipitation period. Similarly, we see long memory in the high northern latitudes in the December ensemble as perturbations are preserved because landatmosphere interactions are hampered by snow cover. These regions coincide with the long memory regions identified by Manabe and Delworth (1990). However, again, the date of initialization is critical, since snowmelt and summer precipitation reduce the memory after the winter period, as seen in the other seasonal ensembles. Only limited agreement can be found between our memory pattern and the soil moisture autocorrelation length shown by Hagemann and Stacke (2015), although the same ESM was used. While for South America and the high northern latitudes some similarities are visible, the extremely long memory exceeding 1 year for most arid regions cannot be confirmed. This might be due to their use of autocorrelation diagnostics, which the authors themselves report to be problematic in very dry and very wet regions. On average, the longest memory is visible for dry soil moisture regimes and the shortest for wet regimes. Within these regions it shows only a low dependency on the type (dry or wet) of the initial perturbation. In terms of temporal variance, long memory is more common in dry periods following distinct rainy seasons and during extensive periods with snow cover.

Although soil moisture memory is often associated with static soil properties such as soil depth (e.g. Asharaf and Ahrens, 2013; Hagemann and Stacke, 2015) we find that soil moisture memory is a dynamical feature, which strongly depends not only on the size of a given anomaly but also on favourable climate conditions. The size of the initial perturbations can explain up to $50 \%$ of the spatial pattern of memory while static parameters such as maximum soil water capacity, rooting depth, or forest fraction are only important for some regions and seasons. Thus, a large part of pattern variance remains and can be assumed to be related to seasonal climate conditions.

Furthermore, soil moisture perturbations affect other land surface states due to different interactions. The strongest impacts are seen for leaf carbon content whose anomalies are associated with a memory of up to 6 months in transitional soil moisture regimes. While the effect on surface temperature is very short-lived and shows much high-frequency variation, the respective anomalies migrate through the soil column into deeper layers and there accumulate to a considerable memory that can even exceed the simulation period of 3 years. Likewise, for most other surface variables, such as humidity and pressure, only a short memory is diagnosed. Soil moisture control seems strong enough to induce some anomalies; however, memory of them is quickly dissipated by strongly non-linear processes in the interacting atmospheric states. Alternatively, it might be possible that anomalies are transported by the atmosphere and might influence the memory in downwind grid cells. Recently, a combination of spatial and temporal feedbacks between soil mois- ture and precipitation was proposed by Guillod et al. (2015); however, this effect cannot be captured by our analysis and its potential influence on soil moisture memory remains open for further study.

A related example for memory recurrence is presented by Guo et al. (2011, 2012), who found that the predictability of atmospheric states due to realistic land surface initialization can recover from a decrease even after one season. This is caused by the existence of persistent land surface anomalies whose impact on the atmosphere increases due to an increase in land-atmosphere coupling strength.

We also find that RootSM memory itself can emerge again after the initial memory had already been lost. In most cases this is related to the existence of a deep-soil moisture storage below the root zone. As all soil layers interact with each other, anomalies which had already faded in upper layers might recur. This is caused by anomalies still existing in lower layers that either modify percolation or - in the case of wet anomalies - can even migrate via upward diffusion. This effect is most common in dry and transitional soil moisture regimes but is quite insensitive to the initialization date and type. Examples of similar processes of interaction between short-term shallow and longer-term deep anomalies exist from earlier studies. These are in particular the transition of temperature signals through several soil layers in the context of force-restore soil schemes (Dickinson, 1988) as well as the propagation from precipitation perturbations into groundwater anomalies (Entekhabi et al., 1992).

From our study, we can conclude that memory is not just the property of a single variable but that it is modified by the interactions of states in a coupled system. Between different states, only one interaction direction is clearly visible in our simulation, from soil moisture to soil temperature and leaf carbon content. However, we do see two-sided interactions between soil moisture in different layers, namely root zone and deep soil. As deep-soil memory exists for the full 3-year simulation period for some regions and feeds back to root zone memory, the predictive potential of soil moisture initialization might be much greater than previously expected. Thus, soil moisture has the potential to play an important role in seasonal predictions. However, there are some limitations to our study which have to be noted. First, in the current version of JSBACH, phase changes within the soil column are not yet considered and, thus, water and energy balances are not connected. However, this process is implemented in the next version (Ekici et al., 2014). It leads to a tight moisture-temperature coupling and might result in significant two-sided memory interactions within the two longmemory states. Whether this will result in long-term stabilization or rather in a quick compensation for anomalies is difficult to predict and needs to be tested. Second, as we initialize all simulations with extreme states, we artificially synchronize extreme events in terms of their temporal occurrence. This could affect soil moisture memory via remote effects between extremes. In order to avoid such interactions 
it would be necessary to preserve a natural pattern of extremes. However, this would require a much larger number of simulations beyond the computational capacities available for this study. Finally, it has to be noted that the results are, of course, model dependent and the exact numbers will differ for individual modelling frameworks. Nonetheless, as long as critical land surface parametrizations exist, namely the separation of the soil column into several layers containing a root zone and a deep-soil layer, we expect similar soil moisture memory characteristics to emerge. Thus, the potential for improved climate predictions should exist for all state-of-the-art modelling frameworks.

Acknowledgements. We acknowledge funding from the Federal Ministry of Education and Research in Germany (BMBF) through the research programme "MiKlip" (FKZ: 01LP1108A). Primary data and scripts used in the analysis and other supplementary information that may be useful in reproducing the authors' work are archived by the Max Planck Institute for Meteorology and can be obtained by contacting publications@mpimet.mpg.de.

The article processing charges for this open-access publication were covered by the Max Planck Society.

Edited by: R. Krishnan

\section{References}

Asharaf, S. and Ahrens, B.: Soil-moisture memory in the regional climate model COSMO-CLM during the Indian summer monsoon season, J. Geophys. Res.-Atmos., 118, 6144-6151, doi:10.1002/jgrd.50429, 2013.

Atlas, R., Wolfson, N., and Terry, J.: The Effect of SST and Soil Moisture Anomalies on GLA Model Simulations of the 1988 U.S. Summer Drought, J. Climate, 6, 2034-2048, doi:10.1175/1520-0442(1993)006<2034:TEOSAS>2.0.CO;2, 1993.

Beljaars, A., Viterbo, P., Miller, M., and Betts, A.: The anomalous rainfall over the United States during July 1993: Sensitivity to land surface parameterization and soil moisture anomalies, Mon. Weather Rev., 124, 362-383, doi:10.1175/15200493(1996)124<0362:TAROTU>2.0.CO;2, 1996.

Betts, A.: Understanding hydrometeorology using global models, B. Am. Meteorol. Soc., 85, 1673-1688, doi:10.1175/BAMS-8511-1673, 2004.

Bony, S., Colman, R., Kattsov, V., Allan, R., Bretherton, C., Dufresne, J.-L., Hall, A., Hallegatte, S., Holland, M., Ingram, W., Randall, D., Soden, B., Tselioudis, G., and Webb, M.: How well do we understand and evaluate climate change feedback processes?, J. Climate, 19, 3445-3482, doi:10.1175/JCLI3819.1, 2006.

Dickinson, R. E.: The Force-Restore Model for Surface Temperatures and Its Generalizations, J. Climate, 1, 1086-1097, doi:10.1175/1520-0442(1988)001<1086:tfmfst>2.0.co;2, 1988.

Dirmeyer, P. and Shukla, J.: Observational and Modeling Studies of the Influence of Soil Moisture Anomalies on Atmospheric Circulation (Review), in: Prediction of Interannual Climate Variations, edited by Shukla, J., Springer Berlin Heidelberg, NATO ASI Series, 6, 1-23, doi:10.1007/978-3-642-76960-3_1, 1993.

Dirmeyer, P. A., Schlosser, C. A., and Brubaker, K. L.: Precipitation, Recycling, and Land Memory: An Integrated Analysis, J. Hydrometeorol., doi:10.1175/2008JHM1016.1, 2009.

Douville, H. and Royer, J.-F.: Sensitivity of the Asian summer monsoon to an anomalous Eurasian snow cover within the Météo-France GCM, Clim. Dynam., 12, 449-466, doi:10.1007/BF02346818, 1996.

Douville, H., Chauvin, F., and Broqua, H.: Influence of Soil Moisture on the Asian and African Monsoons. Part I: Mean Monsoon and Daily Precipitation, J. Climate, 14, 2381-2403, doi:10.1175/1520-0442(2001)014<2381:IOSMOT>2.0.CO;2, 2001.

Ekici, A., Beer, C., Hagemann, S., Boike, J., Langer, M., and Hauck, C.: Simulating high-latitude permafrost regions by the JSBACH terrestrial ecosystem model, Geosci. Model Dev., 7, 631-647, doi:10.5194/gmd-7-631-2014, 2014.

Eltahir, E. A. B.: A Soil Moisture-Rainfall Feedback Mechanism: 1. Theory and observations, Water Resour. Res., 34, 765-776, doi:10.1029/97WR03499, 1998.

Entekhabi, D., Rodriguez-Iturbe, I., and Bras, R. L.: Variability in Large-Scale Water Balance with Land Surface-Atmosphere Interaction, J. Climate, 5, 798-813, doi:10.1175/15200442(1992)005<0798:vilswb>2.0.co;2, 1992.

Ferranti, L. and Viterbo, P.: The European Summer of 2003: Sensitivity to Soil Water Initial Conditions, J. Climate, 19, 3659-3680, doi:10.1175/JCLI3810.1, 2006.

Fischer, E. M., Seneviratne, S. I., Vidale, P. L., Lüthi, D., and Schär, C.: Soil moisture atmosphere interactions during the 2003 european summer heat wave, J. Climate, 20, 5081-5099, doi:10.1175/JCLI4288.1, 2007.

Giorgetta, M. A., Jungclaus, J., Reick, C. H., et al.: Climate and carbon cycle changes from 1850 to 2100 in MPI-ESM simulations for the Coupled Model Intercomparison Project phase 5, JAMES, 5, 572-597, doi:10.1002/jame.20038, 2013.

Guillod, B. P., Orlowsky, B., Miralles, D. G., Teuling, A. J., and Seneviratne, S. I.: Reconciling spatial and temporal soil moisture effects on afternoon rainfall, Nature Communications, 6, 6443, doi:10.1038/ncomms7443, 2015.

Guo, Z., Dirmeyer, P. A., and DelSole, T.: Land surface impacts on subseasonal and seasonal predictability, Geophys. Res. Lett., 38, doi:10.1029/2011g1049945, 2011.

Guo, Z., Dirmeyer, P. A., DelSole, T., and Koster, R. D.: Rebound in Atmospheric Predictability and the Role of the Land Surface, J. Climate, 25, 4744-4749, doi:10.1175/jcli-d-11-00651.1, 2012.

Hagemann, S. and Stacke, T.: Impact of the soil hydrology scheme on simulated soil moisture memory, Clim. Dynam., 44, 17311750, doi:10.1007/s00382-014-2221-6, 2015.

Hohenegger, C., Brockhaus, P., Bretherton, C. S., and Schär, C.: The Soil Moisture-Precipitation Feedback in Simulations with Explicit and Parameterized Convection, J. Climate, 22, 5003-5020, doi:10.1175/2009jcli2604.1, 2009.

Huang, J., van den Dool, H. M., and Georgarakos, K. P.: Analysis of Model-Calculated Soil Moisture over the United States (1931-1993) and Applications to Long-Range Temperature Forecasts, J. Climate, 9, 1350-1362, doi:10.1175/15200442(1996)009<1350:AOMCSM>2.0.CO;2, 1996. 
Jaeger, E. B. and Seneviratne, S. I.: Impact of soil moistureatmosphere coupling on European climate extremes and trends in a regional climate model, Clim. Dynam., 36, 1919-1939, doi:10.1007/s00382-010-0780-8, 2011.

Jeong, J.-H., Linderholm, H. W., Woo, S.-H., Folland, C., Kim, B.-M., Kim, S.-J., and Chen, D.: Impacts of Snow Initialization on Subseasonal Forecasts of Surface Air Temperature for the Cold Season, J. Climate, 26, 1956-1972, doi:10.1175/JCLID-12-00159.1, 2013.

Keenlyside, N. S., Latif, M., Jungclaus, J., Kornblueh, L., and Roeckner, E.: Advancing decadal-scale climate prediction in the North Atlantic sector, Nature, 453, 84-88, doi:10.1038/nature06921, 2008.

Kim, J.-E. and Hong, S.-Y.: Impact of Soil Moisture Anomalies on Summer Rainfall over East Asia: A Regional Climate Model Study, J. Climate, 20, 5732-5743, doi:10.1175/2006JCLI1358.1, 2007.

Koster, R. and Suarez, M.: Soil moisture memory in climate models, J. Hydrometeorol., 2, 558-570, doi:10.1175/15257541(2001)002<0558:SMMICM>2.0.CO;2, 2001.

Koster, R. and Suarez, M.: Impact of land surface initialization on seasonal precipitation and temperature prediction, J. Hydrometeorol., 4, 408-423, doi:10.1175/15257541(2003)4<408:IOLSIO>2.0.CO;2, 2003.

Lin, R., Zhou, T., and Qian, Y.: Evaluation of Global Monsoon Precipitation Changes based on Five Reanalysis Datasets, J. Climate, 27, 1271-1289, doi:10.1175/jcli-d-13-00215.1, 2014.

Manabe, S. and Delworth, T.: The temporal variability of soil wetness and its impact on climate, Climatic Change, 16, 185-192, doi:10.1007/BF00134656, 1990.

Matei, D., Pohlmann, H., Jungclaus, J., Müller, W., Haak, H., and Marotzke, J.: Two tales of initializing decadal climate prediction experiments with the ECHAM5/MPI-OM model, J. Climate, 25, 8502-8523, doi:10.1175/JCLI-D-11-00633.1, 2012.

Meehl, G. A., Goddard, L., Murphy, J., Stouffer, R. J., Boer, G., Danabasoglu, G., Dixon, K., Giorgetta, M. A., Greene, A. M., Hawkins, E., Hegerl, G., Karoly, D., Keenlyside, N., Kimoto, M., Kirtman, B., Navarra, A., Pulwarty, R., Smith, D., Stammer, D., and Stockdale, T.: Decadal prediction: can it be skilful?, B. Am. Meteorol. Soc., 90, 1467-1485, doi:10.1175/2009BAMS2778.1, 2009.

Müller, W. A., Pohlmann, H., Sienz, F., and Smith, D.: Decadal climate predictions for the period 1901-2010 with a coupled climate model, Geophys. Res. Lett., 41, 2100-2107, doi:10.1002/2014GL059259, 2014.

Palmer, T., Andersen, U., Cantelaube, P., Davey, M., Deque, M., Doblas-Reyes, F. J., Feddersen, H., Graham, R., Gualdi, S., Gueremy, J.-F., Hagedorn, R., Hoshen, M., Keenlyside, N., Latif, M., Lazar, A., Maisonnave, E., Marletto, V., Morse, A. P., Orfila, B., Rogel, P., Terres, J.-M., and Thomsen, M. C.: Development of a European Multi-Model Ensemble System for Seasonal to Inter-Annual Prediction (DEMETER), B. Am. Meteorol. Soc., 85, 853-872, doi:10.1175/BAMS-85-6-853, 2004.

Pohlmann, H., Jungclaus, J. H., Köhl, A., Stammer, D., and Marotzke, J.: Initializing Decadal Climate Predictions with the GECCO Oceanic Synthesis: Effects on the North Atlantic, J. Climate, 22, 3926-3938, doi:10.1175/2009JCLI2535.1, 2009.
Raddatz, T. J., Reick, C. H., Knorr, W., Kattge, J., Roeckner, E., Schnur, R., Schnitzler, K. G., Wetzel, P., and Jungclaus, J.: Will the tropical land biosphere dominate the climate-carbon cycle feedback during the twenty-first century?, Clim. Dynam., 29, 565-574, doi:10.1007/s00382-007-0247-8, 2007.

Rowntree, P. R. and Bolton, J. A.: Simulation of the atmospheric response to soil moisture anomalies over Europe, Q. J. Roy. Meteor. Soc., 109, 501-526, doi:10.1002/qj.49710946105, 1983.

Seneviratne, S. I. and Koster, R. D.: A Revised Framework for Analyzing Soil Moisture Memory in Climate Data: Derivation and Interpretation, J. Hydrometeorol., 13, 404-412, doi:10.1175/jhm-d-11-044.1, 2012.

Seneviratne, S. I., Koster, R., Guo, Z., Dirmeyer, P. A., Kowalczyk, E., Lawrence, D., Liu, P., Lu, C.-H., Mocko, D., Oleson, K. W., and Verseghy, D.: Soil moisture memory in AGCM simulations: Analysis of global land-atmosphere coupling experiment (GLACE) data, J. Hydrometeorol., 7, 1090-1112, doi:10.1175/JHM533.1, 2006.

Seneviratne, S. I., Corti, T., Davin, E. L., Hirschi, M., Jaeger, E. B., Lehner, I., Orlowsky, B., and Teuling, A. J.: Investigating soil moisture-climate interactions in a changing climate: A review, Earth-Sci. Rev., 99, 125-161, doi:10.1016/j.earscirev.2010.02.004, 2010.

Shinoda, M. and Nandintsetseg, B.: Soil moisture and vegetation memories in a cold, arid climate, Global Planet. Change, 79, 110-117, doi:10.1016/j.gloplacha.2011.08.005, 2011.

Small, E. E.: The influence of soil moisture anomalies on variability of the North American Monsoon System, Geophys. Res. Lett., 28, 139-142, doi:10.1029/2000GL011652, 2001.

Stevens, B., Giorgetta, M., Esch, M., Mauritsen, T., Crueger, T., Rast, S., Salzmann, M., Schmidt, H., Bader, J., Block, K., Brokopf, R., Fast, I., Kinne, S., Kornblueh, L., Lohmann, U., Pincus, R., Reichler, T., and Roeckner, E.: Atmospheric component of the MPI-M Earth System Model: ECHAM6, JAMES, 5, 146-172, doi:10.1002/jame.20015, 2013.

Taylor, C. M., de Jeu, R. A. M., Guichard, F., Harris, P. P., and Dorigo, W. A.: Afternoon rain more likely over drier soils, Nature, 489, 423-426, doi:10.1038/nature11377, 2012.

Taylor, K. E., Williamson, D., and Zwiers, F.: The sea surface temperature and sea-ice concentration boundary conditions for AMIP II simulations, Tech. Rep. 60, Program for Climate Model Diagnosis and Intercomparison, Lawrence Livermore National Laboratory, Livermore, California, 2000.

Taylor, K. E., Stouffer, R. J., and Meehl, G. A.: An overview of CMIP5 and the experiment design, B. Am. Meteorol. Soc., 93, 485-498, doi:10.1175/BAMS-D-11-00094.1, 2012.

Vinnikov, K. Y. and Yeserkepova, I. B.: Soil Moisture: Empirical Data and Model Results, J. Climate, 4, 66-79, doi:10.1175/15200442(1991)004<0066:SMEDAM>2.0.CO;2, 1991.

$\mathrm{Wu}, \mathrm{W}$. and Dickinson, R. E.: Time Scales of Layered Soil Moisture Memory in the Context of Land-Atmosphere Interaction, J. Climate, 17, 2752-2764, doi:10.1175/15200442(2004)017<2752:TSOLSM>2.0.CO;2, 2004. 